\title{
Key factors during the milling stage of the seed assisted and solvent-free synthesis of MFI and catalytic behavior in the alkylation of phenol with tert-butyl alcohol
}

\author{
Julieth Tatiana García-Sánchez, ${ }^{1}$ (i) Iván Darío Mora-Vergara, ${ }^{1}$ Daniel Ricardo Molina- \\ Velasco, ${ }^{2}$ iD José Antonio Henao-Martínez, ${ }^{3}$ Víctor Gabriel Baldovino-Medrano ${ }^{1,4^{*} \mathbb{C}}$
}

${ }^{1}$ Centro de Investigaciones en Catálisis (CICAT), Parque Tecnológico Guatiguará, km 2 vía El Refugio, Universidad Industrial de Santander, Piedecuesta (Santander), 681011, Colombia.

${ }^{2}$ Laboratorio de Resonancia Magnética Nuclear, Parque Tecnológico Guatiguará, km 2 vía El Refugio, Universidad Industrial de Santander, Piedecuesta (Santander), 681011, Colombia.

${ }^{3}$ Laboratorio de Rayos-X, Parque Tecnológico Guatiguará, km 2 vía El Refugio, Universidad Industrial de Santander, Piedecuesta (Santander), 681011, Colombia.

${ }^{4}$ Laboratorio de Ciencia de Superficies (SurfLab), Parque Tecnológico Guatiguará, km 2 vía El Refugio, Universidad Industrial de Santander, Piedecuesta (Santander), 681011, Colombia.

*Corresponding Author: vicbaldo@uis.edu.co

\begin{abstract}
The so-called mechanochemical method for the synthesis of zeolites reduces the generation of liquid residues and gaseous pollutants as compared to the conventional solvothermal method. Different types of zeolites have been synthesized at the laboratory scale with this method using mostly pestle and mortar. However, such an approach hinders both the systematic comprehension of the effects of the input variables of the milling process and its further scale-up towards the synthesis of the zeolites and their catalytic application. This work investigates the influence of key factors involved in the ball milling stage of the mechanochemical route for the synthesis of MFI done with the assistance of a commercial MFI seed and in the absence of solvents over the most salient physicochemical properties of this type of materials, i.e. the recovery percentage, production cost, morphology, surface area and porosity, crystallinity, acidity of the protonated MFI and catalytic performance. The synthesis of the materials was planned and executed following a full $2^{4}$ factorial experiment whose input variables were the $\mathrm{Na}_{2} \mathrm{O} / \mathrm{SiO}_{2}$ and $\mathrm{H}_{2} \mathrm{O} / \mathrm{SiO}_{2}$ molar ratios and the milling time and speed. The effects of both main and interaction factors over key physicochemical properties, and catalytic behavior of the synthesized materials on the alkylation of phenol with tert-butyl alcohol were established within the explored sampling space. Results showed that the $\mathrm{Na}_{2} \mathrm{O} / \mathrm{SiO}_{2}$ molar ratio plays a key role for the mechanochemical synthesis of MFI, since this variable may direct the synthesis to the preferential production of MOR instead of MFI. On the other hand, it was found that the milling time and speed and their interactions markedly impact the textural properties of MFI. Furthermore, the triple interaction between the input variables affected the concentration of Lewis acid sites of the produced materials. These effects were rationalized by considering that sodium can act as a structure directing agent during the mechanochemical synthesis of MFI and also can promote the incorporation of aluminum to its structure. On the other hand, the milling time and speed are non-linearly correlated to the milling energy required for forming the aluminosilicate precursor that crystallizes during the hydrothermal stage of the process. Overall, all the zeolites synthesized by the mechanochemical route were less crystalline than both the MFI used as seed and an MFI synthesized by solgel. This was associated to the formation of amorphous agglomerates around the zeolitic crystals. Finally, the catalytic behavior of the mechanochemical MFI zeolites in the studied reaction was found to be linearly and positively correlated with both the concentration of Brønsted of sites and with the density of acid sites. The catalytic tendencies were consistent with the proposal of a stepwise Langmuir-Hinshelwood mechanism for the alkylation of phenol with tert-butyl alcohol.
\end{abstract}

Keywords. MFI, zeolite, seed, solvent-free, synthesis, mechanochemical, phenol alkylation, tert-butyl alcohol 


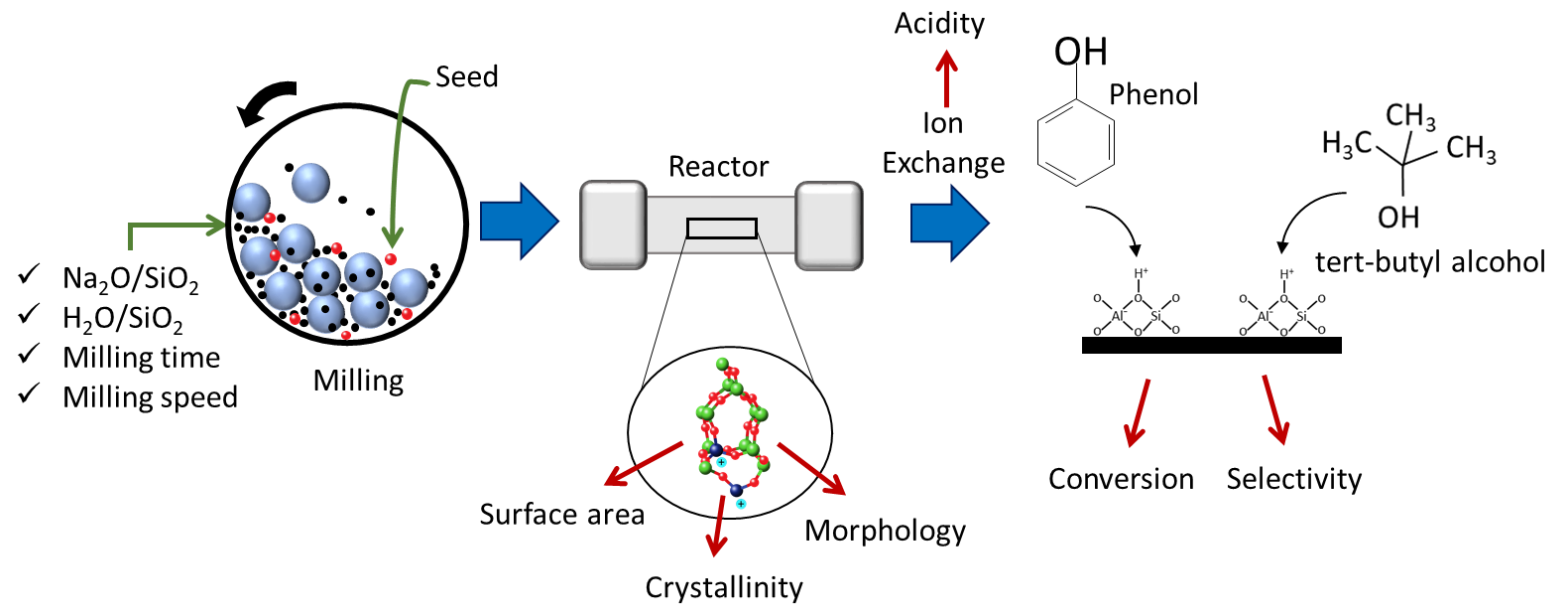

Introduction. Zeolites are crystalline microporous materials generally composed of interconnected $\mathrm{SiO}_{4}$ and $\mathrm{AlO}_{4}^{-}$tetrahedra. The different forms of interconnections that can occur between said tetrahedra give rise to more than one hundred and seventy zeolitic structures. ${ }^{1}$ These materials are known for possessing surface areas up to $\sim 800 \mathrm{~m}^{2} / \mathrm{g}$, acidity up to $\sim 1000 \mu \mathrm{mol} / \mathrm{g}$, pore volumes up to $\sim$ $0.23 \mathrm{~cm}^{3} \mathrm{~g}^{-1}$, and thermal and hydrothermal stability up to $\sim 1000{ }^{\circ} \mathrm{C} .{ }^{1-5}$ Owing to these properties, synthetic zeolites acting either as adsorbents, catalysts or both ${ }^{3,6}$ have been intensively used, since their commercial introduction in the $1940 \mathrm{~s},{ }^{7}$ in industrial processes, daily life products such as detergents, and, more recently, in antioxidative, antiapoptotic and anti-inflammatory pharmaceutics. ${ }^{8}$ Consequently, the zeolite market is estimated to grow from 5.2 billion USD in 2018 to 5.9 billion USD in 2023. ${ }^{9}$

Conventionally, the synthesis of zeolites is carried out by solvothermal processes using large amounts of solvents (water, alcohols, ionic liquids) and organic structuring agents that are mixed and reacted mostly in aqueous phase. ${ }^{3,6}$ During the crystallization stage, the solvent occupies most of the volume ( $\sim 95 \%$ vol) of the reactor hence the yield of the synthesis per reactor volume of the process is low. For example, typical values of $\sim 0.015 \mathrm{~g}$ Beta zeolite per reactor $\mathrm{cm}^{3}$ are reported for the solvothermal process. ${ }^{10}$ In addition, the partial vaporization of the solvent under the conditions of the crystallization stage, $\mathrm{T}=80-$ $250^{\circ} \mathrm{C}$, may lead to pressures up to 20 bar $^{11,12}$ hence making the use of autoclaves mandatory for safety reasons. On the other hand, due to the achieved reaction yields; e.g. $80-86 \%$ for the MFI structure ${ }^{13}$ also known as the Zeolite Socony Mobil-type 5 (ZSM-5) zeolite, ${ }^{14}$ these wastes contain appreciable amounts of valuable unreacted reagents. Therefore, the minimization or elimination of solvents during the production of synthetic zeolites is a target for zeolites manufacturers.

Laboratory works show that the solvent-free synthesis of zeolites is feasible by milling. ${ }^{14-26}$ This method is commonly called mechanochemical. The process involves the same two basic stages of the conventional synthesis: namely, (i) mixing of the aluminum and silicon precursors with the structuring agent and (ii) crystallization, see Figure 1. The difference between both methods is that in the mechanochemical method the mixing stage is done by milling and with minimum or no solvent, of course. In this regard, the milling process is understood as an activation step for the mixture of the solid raw materials. ${ }^{9,14,27}$ Nada et al. ${ }^{17-19}$ described the chemistry of the mixing stage by milling for the production of MFI according to the following equations:

$$
\begin{aligned}
& 2 \mathrm{NH}_{4} \mathrm{X}_{(\mathrm{s})}+\mathrm{Na}_{2} \mathrm{SiO}_{3} \cdot 9 \mathrm{H}_{2} \mathrm{O}_{(\mathrm{s})} \rightarrow \\
& 2 \mathrm{NaX}_{(s)}+\left(\mathrm{NH}_{4}\right)_{2} \mathrm{SiO}_{3(s)}+9 \mathrm{H}_{2} \mathrm{O}_{(l)}(\mathrm{X}=\mathrm{CloF}) \\
& \left(1 \mathrm{NH}_{4}\right)_{2} \mathrm{SiO}_{3(s)}+2 \mathrm{H}_{2} \mathrm{O}_{(l)} \rightarrow 2 \mathrm{NH}_{4} \mathrm{OH}_{(a q)}+\mathrm{H}_{2} \mathrm{SiO}_{3(s)} \\
& 3 \mathrm{Na}_{2} \mathrm{SiO}_{3} \cdot 9 \mathrm{H}_{2} \mathrm{O}+\mathrm{Al}_{2}\left(\mathrm{SO}_{4}\right)_{3} \cdot 18 \mathrm{H}_{2} \mathrm{O} \rightarrow \\
& 3 \mathrm{Na}_{2} \mathrm{SO}_{4}+\mathrm{Al}_{2}\left[\mathrm{SiO}_{3}\right]_{3} \mathrm{l}+45 \mathrm{H}_{2} \mathrm{O}
\end{aligned}
$$

Where, $\mathrm{NH}_{4} \mathrm{X}=\mathrm{NH}_{4} \mathrm{Cl}$ or $\mathrm{NH}_{4} \mathrm{~F}$ is an inorganic structuring directing agent; and $\mathrm{Na}_{2} \mathrm{SiO}_{3} \cdot 9 \mathrm{H}_{2} \mathrm{O}$ and $\mathrm{Al}_{2}\left(\mathrm{SO}_{4}\right)_{3} \cdot 18 \mathrm{H}_{2} \mathrm{O}$ are the silicon and aluminum 
precursors of the material. The chemistry presented above was proposed for a synthesis procedure in which tetrapropylammonium bromide was used as an organic structure directing agent. From these equations, one may conclude that: (i) the reaction precursors contain the water required for the hydrothermal stage themselves. (ii) The milling stage produces the $\mathrm{Al}_{2}\left[\mathrm{SiO}_{3}\right]_{3}$ units from which the zeolitic structure is formed during the hydrothermal step. (iii) The use of a structure directing agent promotes the above reactions during the milling stage. Regarding the latter, for inorganic agents, the chlorine or fluorine ions present in the produced materials must be eliminated by thorough washing hence remaining an issue for waste management. Concerning organic templates, an additional step to the synthesis must be included to eliminate it by calcination. This process generates gaseous pollutants $(\mathrm{NOx})$ as well as greenhouse gases $\left(\mathrm{CO}_{2}\right)$ and an additional expenditure of energy, which increases the carbon footprint of the process. ${ }^{24,28,29}$ Therefore, the minimization or elimination of the use of these agents is desired.

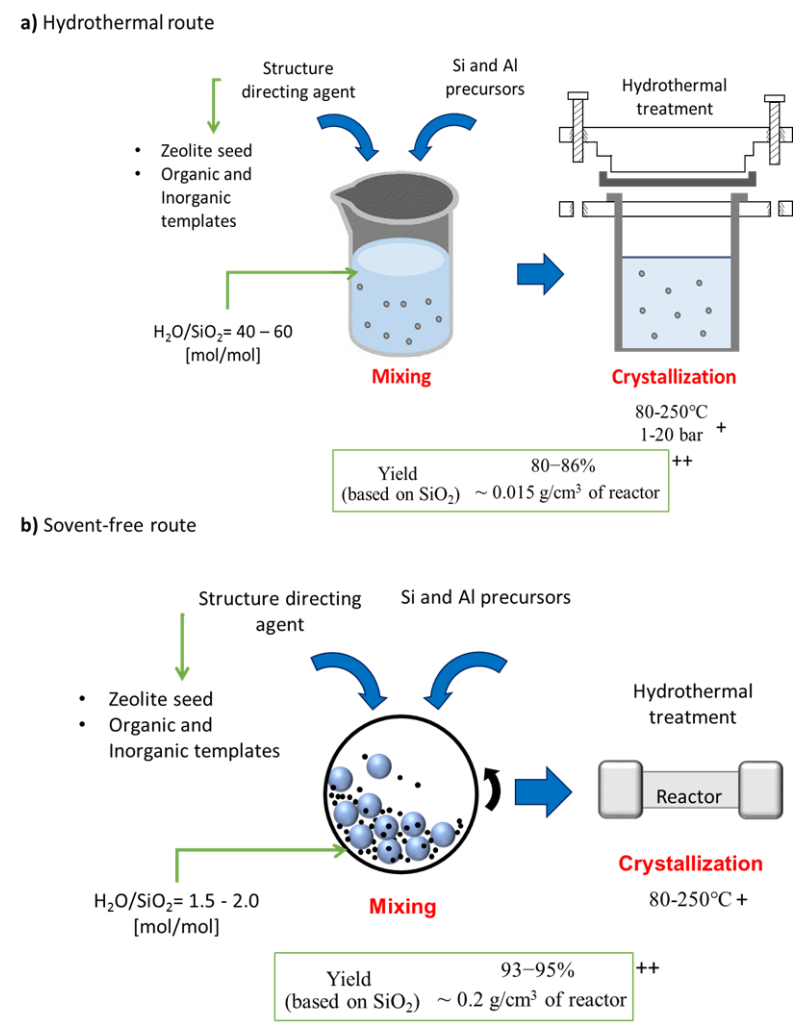

Figure 1. Seed-assisted synthesis of zeolites: a) hydrothermal route and b) solvent-free route. References: $(+)^{11,12}$ and $(++)^{14}$
Xiao et al. ${ }^{10,30}$ did the synthesis of MFI using the mechanochemical method with an MFI seed acting as a structure directing agent. The synthesized materials had similar physicochemical properties to their commercial counterpart (surface area of 345-423 $\mathrm{m}^{2} / \mathrm{g}$ and pore volume of $0.16-0.18 \mathrm{~cm}^{3} / \mathrm{g}$ ). However, the synthesis performed by Xiao et al. ${ }^{10,16,30}$ was made after milling with mortar and pestle which hinders reproducibility and does not allow scale-up. Afterwards, Nada et al. ${ }^{19}$ established some conditions for the synthesis of MFI using ball milling in the absence of an organic structure directing agent. For this purpose, they milled a mixture of $\mathrm{Na}_{2} \mathrm{SiO}_{3} .9 \mathrm{H}_{2} \mathrm{O}$, $\mathrm{SiO}_{2}$, and $\mathrm{Al}_{2}\left(\mathrm{SO}_{4}\right)_{3} \cdot 18 \mathrm{H}_{2} \mathrm{O}$ during at least $50 \mathrm{~min}$ at $1400 \mathrm{rpm}$ and then heated it in an autoclave for no less than $48 \mathrm{~h}$ at $180^{\circ} \mathrm{C}$. These authors used a classical one at the time approach to determine the synthesis conditions which though valid is not the most adequate strategy for scaling up and optimization since it disregards possible non-additivity effects due to the interactions between the corresponding input variables. ${ }^{31}$ To scale up the production of zeolites through a mechanochemical route, it is thus necessary to study and systematically define the effects of both the main and interaction factors intervening during the milling stage on the physicochemical properties of the thus produced zeolites.

The interest on MFI stems from the fact that it is used extensively in industrial processes such as fluid catalytic cracking, ${ }^{32}$ xylene isomerization, ${ }^{33}$ phenol alkylation, ${ }^{34,35}$ and methanol conversion. ${ }^{3,36}$ In the case of the alkylation of phenol, the reaction with tertbutanol (TBA) leads to the production of butyl phenols. Butyl phenols serve as raw materials to produce antioxidants, phenolic resins, agrochemicals, printing inks, and fungicides. ${ }^{37}$ Both the conversion and selectivity of this alkylation reaction depend on the acidity of the zeolite. More specifically, they are controlled by the nature and relative distribution of the acid sites since both Brønsted and Lewis acid sites are reactive. ${ }^{38,39}$ Scheme $\mathbf{1}$ depicts the reaction scheme for the alkylation of phenol with tert-butanol. Accordingly, the reaction allows to produce tert-butyl phenyl ether (t-BPE), 2-tert-butyl-phenol (2-TBP), 4tert-butyl-phenol (4-TBP), and 2,4-di-tert-butyl phenol $(2,4-\mathrm{DTBP}) .{ }^{40}$ 


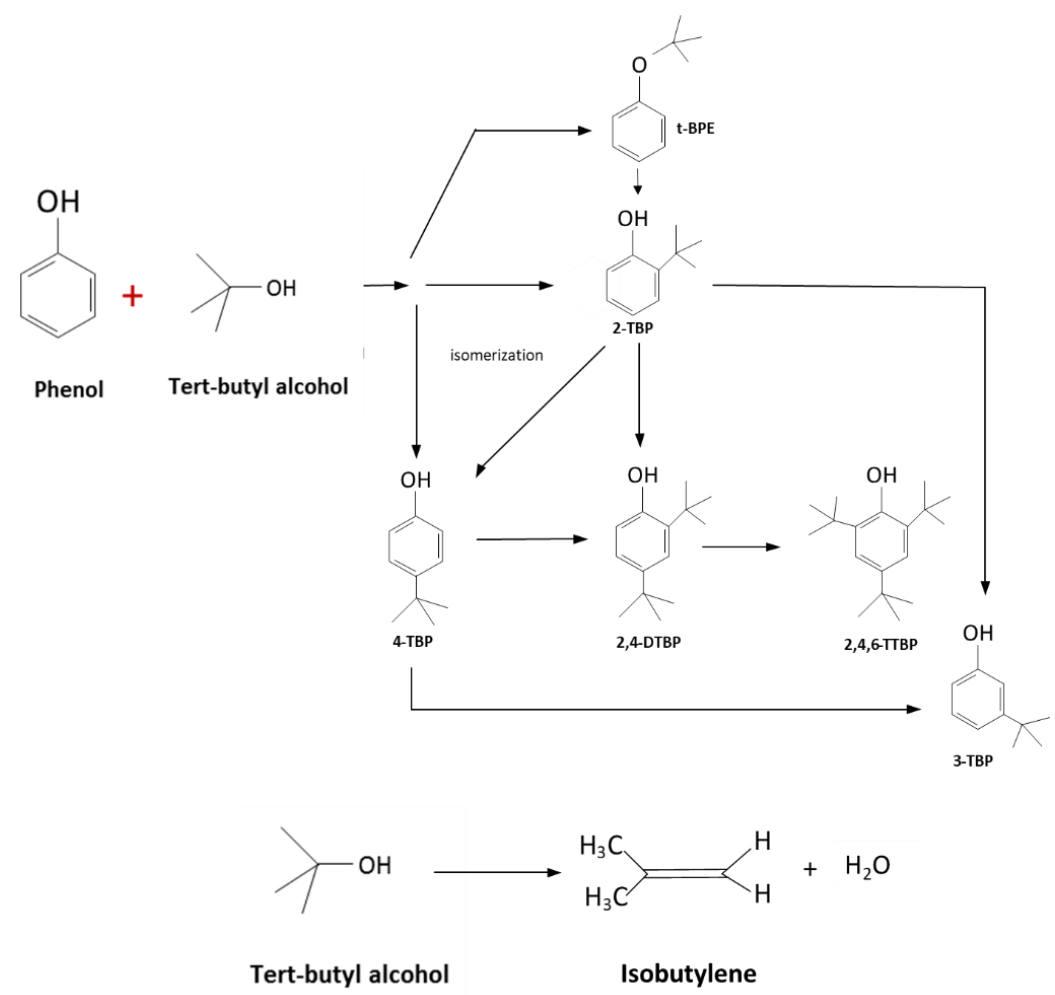

Scheme 1. Reaction scheme for the alkylation of phenol with tert-butyl alcohol using MFI zeolite as a catalyst. ${ }^{40,41}$ Abbreviations: tert-butyl phenyl ether (t-BPE), 2-tert-butyl-phenol (2-TBP), 4-tert-butyl-phenol (4-TBP), 3-tert-butylphenol (3-TBP), 2,4-di-tert-butyl phenol (2,4 DTBP) and 2,4,6-tri-tert-butyl phenol (2,4,6-TTBP).

In this work, the synthesis of MFI was carried out by a seed-assisted and solvent-free mechanochemical method with a focus on assessing the effect of the key factors of the ball milling stage of the process over the properties of the thus produced materials. Following the literature, ${ }^{9,14,18-20}$ the input variables selected for the experimental design were the $\mathrm{Na}_{2} \mathrm{O} / \mathrm{SiO}_{2}$ and $\mathrm{H}_{2} \mathrm{O} / \mathrm{SiO}_{2}$ molar ratios and the milling time and speed. The experiment consisted on planning and performing a full $2^{4}$ factorial design that allowed assessing the effects of the main and interaction factors over the recovery and production cost of the materials, their morphology, crystallinity, surface area, and porosity. Further transformation of the produced zeolites into their protonated counterparts allowed investigating how their acidity influences their catalytic behavior in the alkylation of phenol with tert-butyl alcohol. Results showed that the $\mathrm{Na}_{2} \mathrm{O} / \mathrm{SiO}_{2}$ molar ratio was the most influential factor because it directed the structure formed during synthesis. On the other hand, the milling energy; i.e. the combined effect of milling time and speed, influences the final characteristics of the zeolites up to a certain point, after which it is not necessary to supply more energy. Finally, it was established that the $\mathrm{H}_{2} \mathrm{O} / \mathrm{SiO}_{2}$ molar ratio had a weak effect on the properties of the produced zeolites. Furthermore, the addition of water increased the percentage of recovery of the material during the synthesis. Regarding the catalytic performance, the results showed that the main product of the alkylation reaction of phenol with tert-butanol was tert-butyl phenyl ether followed by lower proportions of 2-tertbutyl-phenol, 4-tert-butyl-phenol, 3-tert-butylphenol and 2,4-di-tert-butyl phenol. Finally, based on the result, a Langmuir-Hinshelwood mechanism was proposed for the alkylation of phenol with tert-butyl alcohol.

2. Results and discussion. The section is divided into two main parts: one for the materials synthesized with a $\mathrm{Na}_{2} \mathrm{O} / \mathrm{SiO}_{2}=0.4$ molar ratio and another for those synthesized with a $\mathrm{Na}_{2} \mathrm{O} / \mathrm{SiO}_{2}=0.2$ molar ratio. The reason for this was that the former conditions led to very poor recovery percentages. Therefore, for the materials with $\mathrm{Na}_{2} \mathrm{O} / \mathrm{SiO}_{2}=0.4$, a rather brief analysis of the physicochemical properties is provided, and for the materials with $\mathrm{Na}_{2} \mathrm{O} / \mathrm{SiO}_{2}=0.2$ a more thorough study was done.

2.1. Results for the materials synthesized with a $\mathrm{Na}_{2} \mathrm{O} / \mathrm{SiO}_{2}=0.4$ molar ratio. In this case, only the 
materials marked as Z-Na0.4-H1.7-T5-S200 and Z-

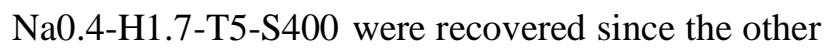
materials remained firmly attached to the milling jar (Please see, Figure S4). Furthermore, the recovery percentage of Z-Na0.4-H1.7-T5-S200 and Z-Na0.4H1.7-T5-S400 was below 23\%, see Table 1. Table 1 also presents the approximate cost of producing one gram of each synthesized material, as based solely on the cost of the reagents in a laboratory scale presentation $(500 \mathrm{~g}-5 \mathrm{~kg})$. It can be noticed that the nominal cost of these two materials is larger than 1.00 USD/g because of their poor recovery percentage. Therefore, a process for producing MFI under these conditions seems economically unviable.

Figure 2 shows SEM micrographs from a sample of Z-Na0.4-H17-T5-S200 and from a sample of the MFI seed. Rod-shaped crystals were observed for both samples. ATR and XRD analyses allowed establishing that these rods are crystals of MOR. Indeed, the ATR spectra featured in Figure 3 shows that both samples of the materials synthesized with the $\mathrm{Na}_{2} \mathrm{O} / \mathrm{SiO}_{2}=0.4$ molar ratio had spectra analogous to that of a commercial MOR sample, CBV 21A. A further comparison of these spectra with the one of the seed, CBV 2314, shows that the absorption bands at 550 and $1225 \mathrm{~cm}^{-1}$ of MFI are absent for both the samples of the synthesized materials and the commercial MOR. Therefore, it is suggested that MFI was not formed under these conditions. Figure 4 showing the XRD diffraction patterns of the commercial MOR and a selected sample of the materials synthesized with the $\mathrm{Na}_{2} \mathrm{O} / \mathrm{SiO}_{2}=0.4$ molar ratio further confirmed that these materials are basically MOR. Indeed, according to calculations, equation S3, $90 \%$ of this solid was MOR. On the other hand, SEM-EDS showed that these materials had a Si/Al molar ratio 4.4 , which is less than half the $\mathrm{Si} / \mathrm{Al}$ molar ratio $(\sim 10)$ of the commercial MFI. Accordingly, for the $\mathrm{Na}_{2} \mathrm{O} / \mathrm{SiO}_{2}=$ 0.4 molar ratio the amount of aluminum incorporated into the material was higher.
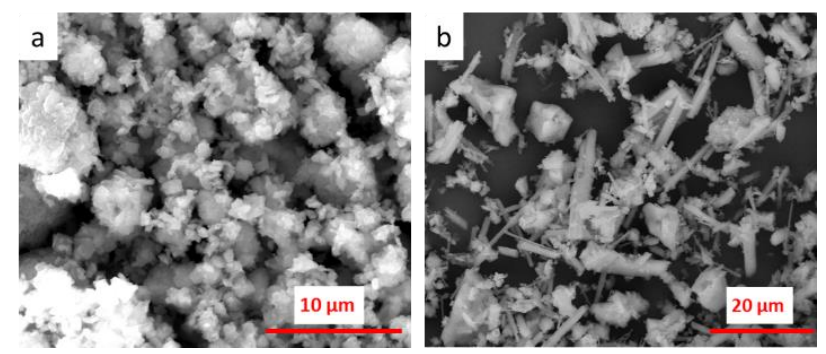

Figure 2. Micrographs of the MFI seed (a) and the sample Z-Na0.4-H1.7-T5-S200 (b). Sample nomenclature: ZNa\#-H\#-T\#-S\#, where $\mathrm{Na}$ and $\mathrm{H}$ correspond to the $\mathrm{Na}_{2} \mathrm{O} / \mathrm{SiO}_{2}$ and to the $\mathrm{H}_{2} \mathrm{O} / \mathrm{SiO}_{2}$ molar ratios, respectively, and $\mathrm{T}$ and $\mathrm{S}$ to the milling time and speed, respectively.

Table 1. Recovery percentage of the synthesized materials expressed as the mass ratio of recovered zeolite/( $\left.\mathrm{SiO}_{2}+\mathrm{Al}_{2} \mathrm{O}_{3}\right)$, where $\mathrm{SiO}_{2}$ and $\mathrm{Al}_{2} \mathrm{O}_{3}$ correspond to the amount of these reagents in the initial mixture and their sum is the expected weight. The production cost is based solely on the cost of the reagents.

\begin{tabular}{lcccc}
\hline \multicolumn{1}{c}{ Material code } & Expected weight [g] & Recovered weight [g] Recovery [\%] & $\begin{array}{c}\text { Production cost } \\
{[\text { USD/g] }}\end{array}$ \\
\hline \hline Z-Na0.2-H1.7-T5-S200 & 2.2732 & 1.4636 & 64.4 & 0.44 \\
Z-Na0.2-H2.0-T5-S200 & 2.3218 & 2.1022 & 90.5 & 0.31 \\
Z-Na0.2-H1.7-T5-S400 & 2.7017 & 1.6480 & 61.0 & 0.46 \\
Z-Na0.2-H2.0-T5-S400 & 2.5650 & 1.9391 & 75.6 & 0.37 \\
Z-Na0.2-H1.7-T16-S200 & 2.7146 & 1.5851 & 58.4 & 0.48 \\
Z-Na0.2-H2.0-T16-S200 & 2.6030 & 2.0967 & 80.5 & 0.35 \\
Z-Na0.2-H1.7-T16-S400 & 2.6512 & 1.6115 & 60.8 & 0.47 \\
Z-Na0.2-H2.0-T16-S400 & 2.5232 & 2.1415 & 84.9 & 0.33 \\
Z-Na0.4-H1.7-T5-S200 & 2.0654 & 0.2576 & 12.5 & 2.66 \\
Z-Na0.4-H1.7-T5-S400 & 2.1186 & 0.4799 & 22.7 & 1.47 \\
MFI S-G & 2.9693 & 1.9979 & 67.3 & 0.38 \\
\hline
\end{tabular}




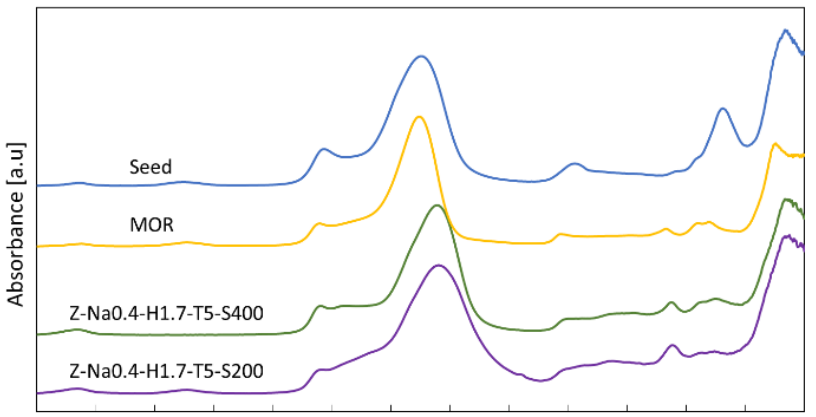

$\begin{array}{llllllllllllll}1700 & 1600 & 1500 & 1400 & 1300 & 1200 & 1100 & 1000 & 900 & 800 & 700 & 600 & 500 & 400\end{array}$ Wavenumber $\left[\mathrm{cm}^{-1}\right]$

Figure 3. ATR-FTIR of the synthesized samples at molar ratio $\mathrm{Na}_{2} \mathrm{O} / \mathrm{SiO}_{2}=0.4$, the MOR zeolite CBV 21 A and the seed zeolite (CBV 2314). Samples nomenclature: Z-Na\#$\mathrm{H} \#-\mathrm{T} \#-\mathrm{S} \#$, where $\mathrm{Na}$ and $\mathrm{H}$ correspond to the $\mathrm{Na}_{2} \mathrm{O} / \mathrm{SiO}_{2}$ and to the $\mathrm{H}_{2} \mathrm{O} / \mathrm{SiO}_{2}$ molar ratios, respectively, and $\mathrm{T}$ and $\mathrm{S}$ to the milling time and speed, respectively.

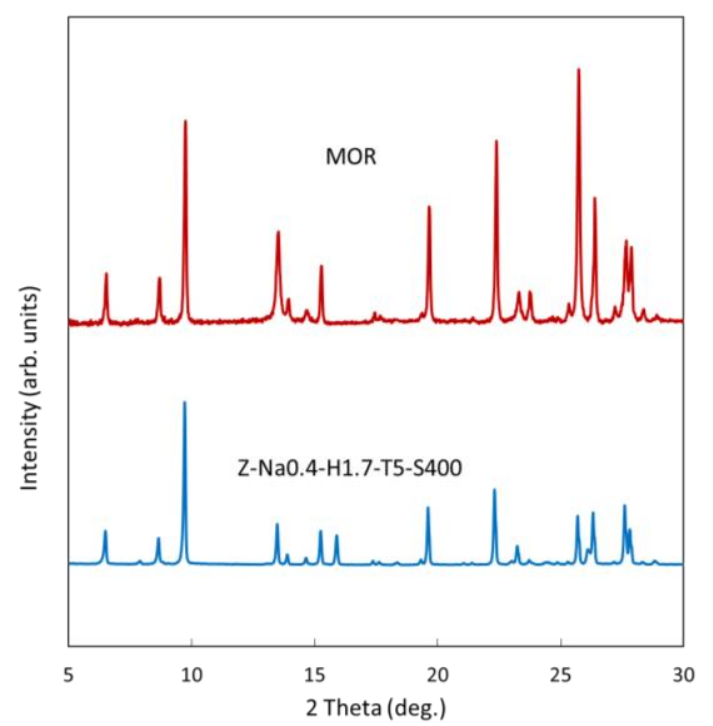

Figure 4. XRD patterns of the sample Z-Na0.4-T5-S400H1.7, a commercial MOR (CBV 21A), and the seed zeolite (CBV 2314). In the nomenclature, $\mathrm{Na}$ and $\mathrm{H}$ correspond to the $\mathrm{Na}_{2} \mathrm{O} / \mathrm{SiO}_{2}$ and to the $\mathrm{H}_{2} \mathrm{O} / \mathrm{SiO}_{2}$ molar ratios, respectively, and $\mathrm{T}$ and $\mathrm{S}$ to the milling time and speed, respectively.

Figure 5 presents the $\chi$-plot ${ }^{42}$ representation of the Ar adsorption-desorption isotherms for samples of the materials synthesized with $\mathrm{Na}_{2} \mathrm{O} / \mathrm{SiO}_{2}=0.4$, a) and b), and for samples of the benchmark zeolites (i.e. commercial MOR and MFI), c) and d), respectively. Section S4 presents the adsorption isotherms without the $\chi$-modification. All the samples showed Type I adsorption isotherms characteristic of microporous solids. ${ }^{43}$ The $\chi$-plots for the samples of both the synthesized materials and the commercial MOR showed a change in slope at the beginning of the isotherm (see arrows in Figure 5) which indicates the presence of two families of micropores. This is consistent with the microporous network of mordenite which is formed by channels of $6.5 \times 7.0$ $\AA$ connected by $2.6 \times 5.7 \AA$ tortuous pores. ${ }^{44}$ Conversely, MFI, which did not exhibit this change in slope in its $\chi$-plot, Figure 5d, may be considered to have a single family of micropores because it has channels of $5.5 \AA \times 5.1 \AA$ that intersect other straight channels of $5.6 \AA$ x $5.3 \AA$. $^{45}$
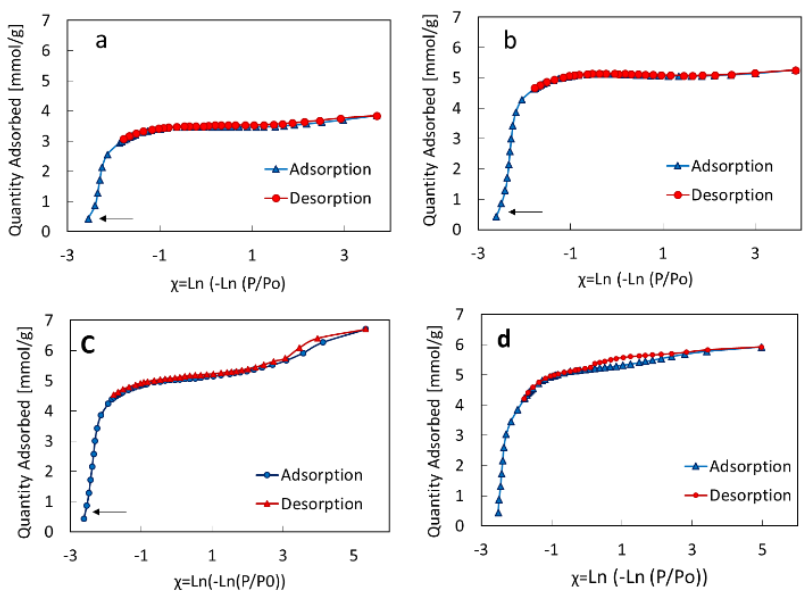

Figure 5. Argon adsorption-desorption isotherms of synthesized samples with a $\mathrm{Na}_{2} \mathrm{O} / \mathrm{SiO}_{2}=0.4$. a) Z-Na0.4H1.7-T5-S200, b) Z-Na0.4-H1.7-T5-S400, c) MOR and d) seed. Where, $\mathrm{Na}$ and $\mathrm{H}$ correspond to the $\mathrm{Na}_{2} \mathrm{O} / \mathrm{SiO}_{2}$ and to the $\mathrm{H}_{2} \mathrm{O} / \mathrm{SiO}_{2}$ molar ratios, respectively, and $\mathrm{T}$ and $\mathrm{S}$ to the milling time and speed, respectively.

Considering the presented evidence, the solids formed using a $\mathrm{Na}_{2} \mathrm{O} / \mathrm{SiO}_{2}$ molar ratio of 0.4 were MOR zeolites. On the other hand, increasing the milling speed from 200 to $400 \mathrm{rpm}$ during the synthesis raised $\sim 33 \%$ the surface area of the synthesized zeolites; namely, Z-Na0.4-H1.7-T5S200 had a surface area of $280 \mathrm{~m}^{2} / \mathrm{g}$ while Z-Na0.4H1.7-T5-S400 had a surface area of $419 \mathrm{~m}^{2} / \mathrm{g}$. These zeolites had a lower surface area than the sample of commercial MOR, $497 \mathrm{~m}^{2} / \mathrm{g}$, nonetheless. Regarding the acidity of the ion exchanged zeolites, Z-Na0.4H1.7-T5-S200 had a lower density of acid sites, Brønsted + Lewis, than the commercial MOR and, therefore, a lower conversion in phenol tertbutylation. Particularly, a sample from Z-Na0.4H1.7-T5-S200 had an acidity of $0.09 \mathrm{mmol} / \mathrm{g}$ and converted $3.9 \%$ phenol, while a sample from the commercial MOR had an acidity of $1.24 \mathrm{mmol} / \mathrm{g}$ and converted $16.7 \%$ phenol. This relationship is due to the fact that the conversion of phenol depends on the 
total number of acidic sites and can occur at both the Brønsted and Lewis sites. ${ }^{39,46}$

2.2 Results for the materials synthesized with a $\mathrm{Na}_{2} \mathrm{O} / \mathrm{SiO}_{2}=0.2$ molar ratio. Figure 6 shows the statistical assessment of the data for the recovery percentage of the materials synthesized with the $\mathrm{Na}_{2} \mathrm{O} / \mathrm{SiO}_{2}=0.2$ molar ratio. Supplementary main and double interaction plots are presented in Figure S5. According to results, increasing the amount of water (via the $\mathrm{H}_{2} \mathrm{O} / \mathrm{SiO}_{2}$ molar ratio) during the synthesis had a positive effect on the percentage of recovery of the materials, see the Effects column and $p$-values in the ANOVA table included in Figure 6. Indeed, among the studied input variables, the $\mathrm{H}_{2} \mathrm{O} / \mathrm{SiO}_{2}$ molar ratio had the strongest effect over the recovery percentage, while the other experimental factors had weak effects, Figures 6 and S5, hence being statistically negligible at a confidence level above
$90 \%$. The results of this analysis are in good agreement with what was observed for the materials synthesized with the $\mathrm{Na}_{2} \mathrm{O} / \mathrm{SiO}_{2}=0.4$ molar ratio, where, despite the problems on the synthesis commented earlier, the $\mathrm{H}_{2} \mathrm{O} / \mathrm{SiO}_{2}$ molar ratio also had a positive effect on the recovery percentage. On the other hand, a higher recovery percentage translated into a lower production cost. Therefore, under the studied production scale and within the sampling space of this work, the material labeled as $\mathrm{Z}-\mathrm{Na} 0.2-$ H2.0-T5-S200 had the lowest production cost; 0.31 USD/g. This cost was lower than the one for the solgel MFI, $0.38 \mathrm{USD} / \mathrm{g}$. This difference in production costs might seem narrow, but it is an incentive for further scaling-up since the costs of bench-scale synthesis are almost always higher than those at the pilot and industrial level scales, and one of the reasons for this is that the recovery percentage of the material is always lower at the bench-scale.

\begin{tabular}{ccccccccc}
\hline Factor & Effect & Type of effect & SS $^{*}$ & \%Contribution SS & DF $^{* *}$ & MS $^{* * *}$ & F & p-Value \\
\hline \hline T & -1.725 & Negative & 5.951 & 0.56 & 1 & 5.951 & 0.261 & 0.699 \\
$\mathrm{~S}$ & -2.875 & Negative & 16.531 & 1.56 & 1 & 16.531 & 0.726 & 0.551 \\
$\mathrm{H}$ & 21.725 & Positive & 943.951 & 89.03 & 1 & 943.951 & 41.435 & 0.098 \\
$\mathrm{TS}, \mathrm{ST}$ & 6.275 & Ant & 78.751 & 7.43 & 1 & 78.751 & 3.457 & 0.314 \\
$\mathrm{TH}, \mathrm{HT}$ & 1.375 & Ant & 3.781 & 0.36 & 1 & 3.781 & 0.166 & 0.754 \\
$\mathrm{SH}, \mathrm{HS}$ & -2.375 & Syn*/Ant & 11.281 & 1.06 & 1 & 11.281 & 0.495 & 0.610 \\
TSH & 3.375 & N.A. & N.D. & N.D & 0 & N.D & N.D & N.D \\
Total & & & 1083.029 & & 7 & 154.718 & & \\
Error & & 22.781 & & 1 & 22.781 & & \\
\hline
\end{tabular}

$*$ Sum of Squares
$* *$ Degrees of Freedom
$* * *$ Mean Square
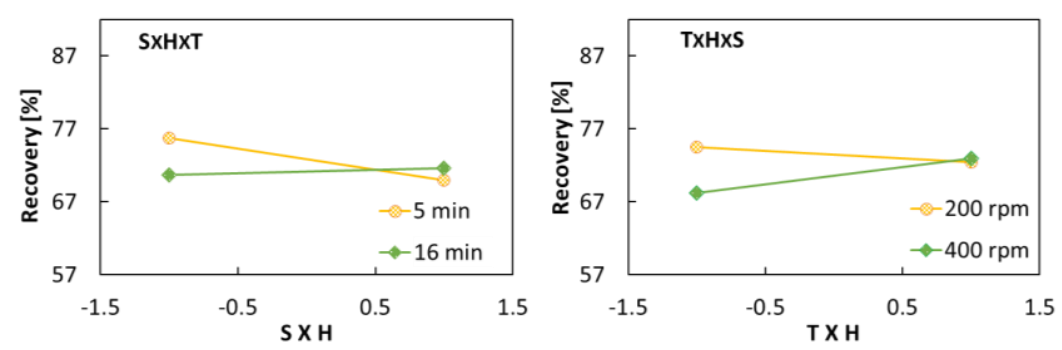

Synergistic

Antagonistic

N.A: Not Applicable

N.D: Not Determined

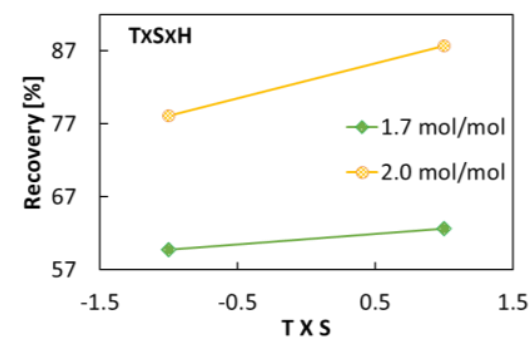

Figure 6. ANOVA table and interaction plots for assessing the effect of the triple factor of the synthesis variables on the recovery percentage of the solvent-free seed-assisted synthesis of zeolites. In the nomenclature: $\mathrm{Na}$ and $\mathrm{H}$ correspond to the $\mathrm{Na}_{2} \mathrm{O} / \mathrm{SiO}_{2}$ and to the $\mathrm{H}_{2} \mathrm{O} / \mathrm{SiO}_{2}$ molar ratios, respectively, and $\mathrm{T}$ and $\mathrm{S}$ to the milling time and speed, respectively. 
2.2.1 Analysis of the morphology and chemical composition of the materials. Figure 7 shows SEM micrographs for a selected sample of the synthesized materials; specifically, the figure shows micrographs for a sample of the material Z-Na0.2-H1.7-T5-S200 taken before (a) and after (b) the hydrothermal treatment. In addition, micrographs for a sample of the seed (c) and for the sol-gel MFI (d) are presented for comparison purposes. SEM images for the rest of the materials are shown in Figure S30. The analysis of the sample measured before the hydrothermal treatment, Figure 7a, showed that the crystals from the seed were surrounded by small agglomerates whose borders were not well defined, see the parts of the figure encircled with dashed lines. These agglomerates could be related to the aluminosilicate matrix produced during ball milling. In this sense, Ren et al. ${ }^{47}$ postulated that the seed provides nuclei around which the aluminosilicate matrix forms new crystals. After the hydrothermal treatment, Figure $\mathbf{7 b}$, small crystals with defined edges were formed hence showing that the amorphous aluminosilicate matrix obtained by ball milling transformed into a zeolite.

In general, the mechanochemically synthesized materials showed mainly cubic crystals which were similar to those found for the seed, Figure 7c. However, some rod-shaped crystals were also observed, Figure 7b. As found earlier, Section 2.1, these are MOR crystals. On the other hand, the solgel MFI, Figure 7d, showed finer and larger orthorhombic crystals than those obtained for the zeolites synthesized by the mechanochemical route. Some authors have proposed that this is due to the fact that the energy supplied in the milling stage generates a reduction in the size of the seed which leads to a dispersion of nucleation centers, hence producing smaller crystals and, under some conditions, even leading to some degree of amorphization of the seed during ball milling. ${ }^{48-51}$

Results from SEM-EDS are reported in Table 2. The materials synthesized with the mechanochemical method had a rather constant $\mathrm{Si} / \mathrm{Al}$ molar ratio of $~$ 8.5 which was lower than the one of the seed. Thus, the zeolites synthesized by the mechanochemical route were richer in aluminum than their commercial counterpart. This tendency may be related to the concentration of $\mathrm{Na}^{+}$cations in the synthesis and to their role as structure-directing agents. ${ }^{19,52-53}$ Conventionally, organic cations, e.g. quaternary ammonia, are used for the formation of the MFI structure. These cations are larger than sodium cations. It is in this sense that a higher loading of sodium cations is necessary to direct the porous structure compared to an organic agent. This in turn facilitates the incorporation of more $\mathrm{Al}$ atoms into the structure of the zeolite for balancing the charge of the $\mathrm{Na}^{+}$cation. ${ }^{54}$ Therefore, a higher loading of sodium during the synthesis can favor a higher loading of aluminum in zeolites. The increase in the concentration of sodium and thence the increase in the amount of $\mathrm{Al}$ in the structure of the zeolite led to the formation of MOR, as evidenced in the XRD results (Figure 4). Overall, MOR is a more thermodynamically stable phase than MFI, see Figure 8. ${ }^{20,52,55}$
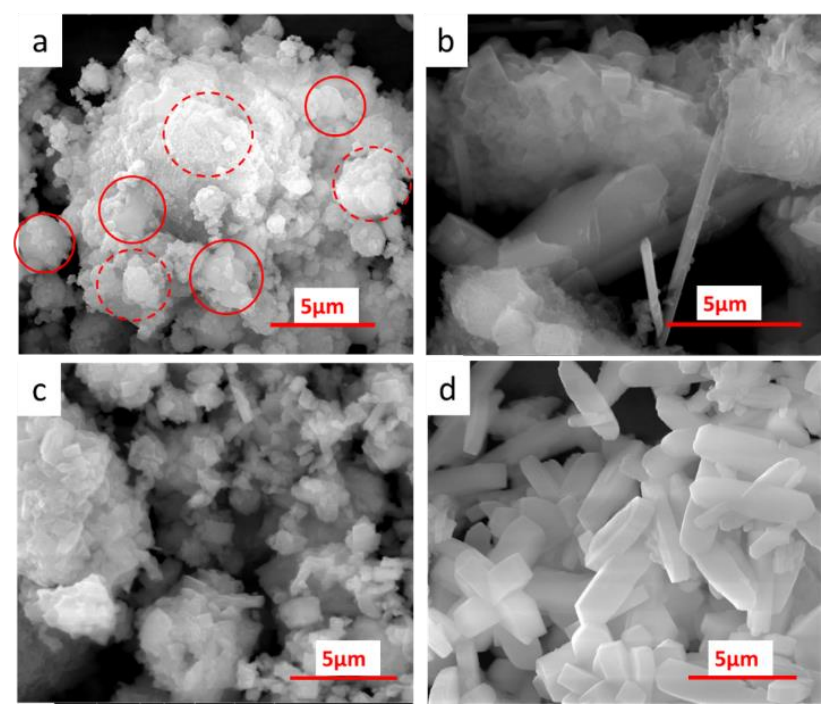

Figure 7. Micrographs of a sample of Z-Na0.2-H1.7-T5S200 before (a) and after (b) the hydrothermal treatment, the seed (c) and a sol-gel MFI (d). The circles with continuous lines show fragments with defined edges that could be associated with seed zeolite crystals surrounded by small amorphous agglomerates, see circles with dashed lines.

Table 2. Si/Al ratios obtained through the SEM-EDS technique for some selected samples and the seed zeolite.

\begin{tabular}{lc}
\hline \multicolumn{1}{c}{ Material code } & Si / Al \\
\hline \hline Seed & 10.3 \\
Z-Na0.2-H2.0-T5-S200 & 8.4 \\
Z-Na0.2-H1.7-T5-S400 & 8.3 \\
Z-Na0.2-H1.7-T16-S400 & 8.6 \\
Z-Na0.4-H1.7-T5-S200 & 4.4 \\
\hline
\end{tabular}




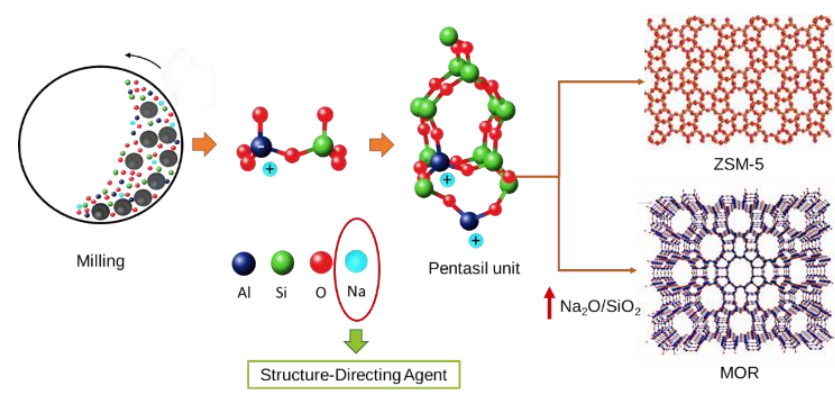

Figure 8. Production of MOR impurities during MFI zeolite synthesis for high $\mathrm{Na}_{2} \mathrm{O} / \mathrm{SiO}_{2}$ molar ratios because the $\mathrm{Na}^{+}$cation acts as a structure directing agent during synthesis.

2.2.2 Chemical structure. Figure 9 presents ATR spectra for samples from a representative material, Z$\mathrm{Na} 0.2-\mathrm{H} 1.7-\mathrm{T} 16-\mathrm{S} 200$, obtained by the mechanochemical method at three stages of the synthesis process: after milling without washing (Z$\mathrm{Na} 0.2-\mathrm{H} 1.7-\mathrm{T} 16-\mathrm{S} 2004)$, after washing the material recovered from the milling stage $(\mathrm{Z}-\mathrm{Na} 0.2-\mathrm{H} 1.7-$ T16-S20054), and after the hydrothermal treatment (Z-Na0.2-H1.7-T16-S200). Spectra for the seed and for the sol-gel MFI are also presented for comparison purposes. ATR spectra for the rest of the materials are shown in Figure S31. The spectra for the samples of Z-Na0.2-H1.7-T16-S200 showed two bands at 550 and $1225 \mathrm{~cm}^{-1}$ that are characteristic of the fivemembered rings of the pentasil structural unit and to the vibration of the asymmetric stretching of the $\mathrm{SiO}_{4}$ and $\mathrm{AlO}_{4}{ }^{-}$tetrahedra, respectively. ${ }^{56,57}$ This can be corroborated from the spectra recorded for both the seed and the sol-gel MFI, Figure 9. The same bands were not found for the samples of the material recovered after milling before and after washing, Z$\mathrm{Na} 0.2-\mathrm{H} 1.7-\mathrm{T} 16-\mathrm{S} 200 \%$ and Z-Na0.2-H1.7-T16S2004\%, respectively. Instead, the spectra showed two broad shoulders in this region. Therefore, there was no evidence that the zeolite formed during the milling process. The sample Z-Na0.2-H1.7-T16-S200\% showed two bands at 637 and $615 \mathrm{~cm}^{-1}$, Figure 9, which disappeared after washing, see spectrum for Z$\mathrm{Na} 0.2-\mathrm{H} 1.7-\mathrm{T} 16-\mathrm{S} 20054$. These bands were ascribed to $\mathrm{Na}_{2} \mathrm{SO}_{4}{ }^{58}$ and their disappearance during washing can be explained by the high solubility of this compound in water (the solubility of $\mathrm{Na}_{2} \mathrm{SO}_{4}$ in water is $288.9 \mathrm{~g} / \mathrm{kg}$ at $30^{\circ} \mathrm{C}^{59,60}$ ). This result agrees with the proposal made by Nada et al. ${ }^{19}$ in regards to the chemistry developed during the milling stage (eq. 3).

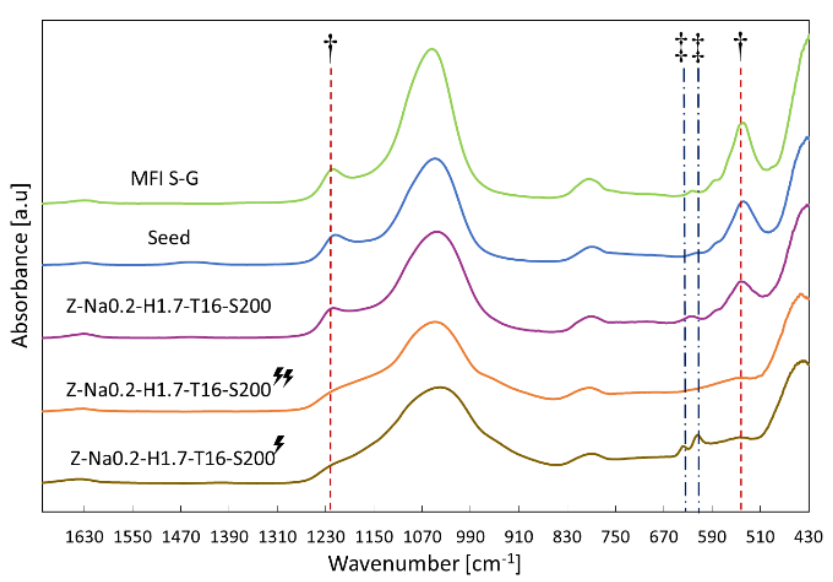

Figure 9. ATR-FTIR spectra with the presence of the characteristic bands of the MFI in the seed zeolite (CBV 2314), the MFI zeolite synthesized by the sol-gel method (MFI S-G), the sample of Z-Na0.2-H1.7-T16-S200, a sample after milling without washing (Z-Na0.2-H1.7-T16S2005) after washing the material recovered from the milling stage (Z-Na0.2-H1.7-T16-S200\%4). $\dagger$ corresponds to MFI bands and $\ddagger$ corresponds to $\mathrm{Na}_{2} \mathrm{SO}_{4}$ bands. Sample nomenclature: $\mathrm{Na \#}$ is the $\mathrm{Na}_{2} \mathrm{O} / \mathrm{SiO}_{2}$ molar ratio, $\mathrm{T}$ is the milling time, $\mathrm{S} \#$ is the milling speed and $\mathrm{H} \#$ is the $\mathrm{H}_{2} \mathrm{O} / \mathrm{SiO}_{2}$ molar ratio.

2.2.3 Crystallinity. Diffraction patterns for one selected sample of the mechanochemically synthesized materials before and after the hydrothermal treatment, Z-Na0.2-H1.7-T16-S400 s and Z-Na0.2-H1.7-T16-S400, respectively, together with the patterns of the MFI seed, the sol-gel MFI, and of the commercial MOR are shown in Figure 10. XRD patterns for the rest of the materials are shown in Figure S32. In general, the diffraction pattern for Z-Na0.2-H1.7-T16-S400 confirms the formation of MFI by the mechanochemical method as it was deduced from the analysis of the ATR spectra, Figure 9. XRD results also confirmed that zeolitic crystals were not formed after milling, see the pattern for the sample Z-Na0.2-H1.7-T16-S4009. For the latter, XRD peaks associated with $\mathrm{Na}_{2} \mathrm{SO}_{4}$ (PDF 05-0831 and PDF 01-1009) were found thence further confirming previous conclusions from the analysis of the ATR spectra. 


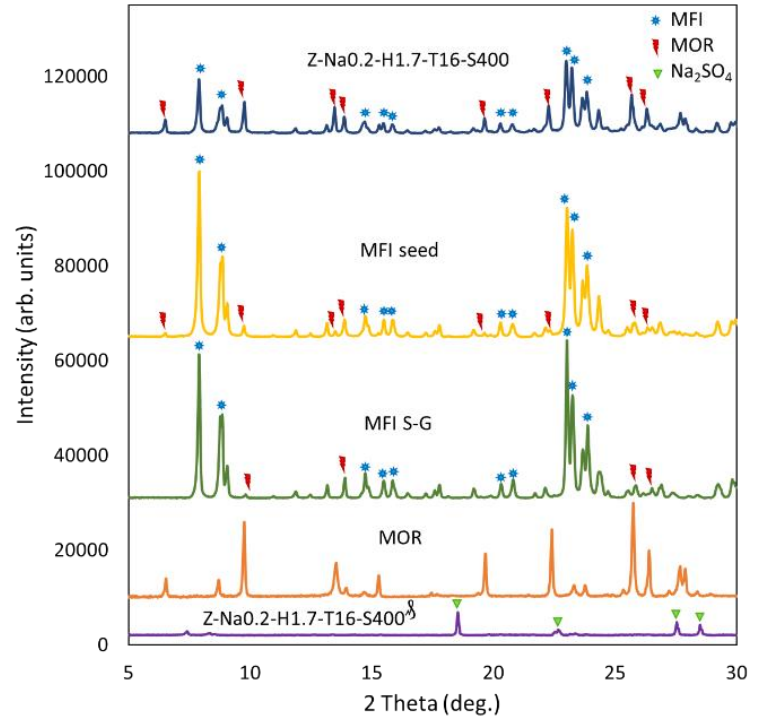

Figure 10. XRD patterns of a selected synthesized zeolite before (Z-Na0.2-H1.7-T16-S400 $\left.{ }^{\natural}\right)$ and after (Z-Na0.2H1.7-T16-S400) the hydrothermal treatment, the MFI seed (CBV 2314), a commercial MOR zeolite (CBV 21A), and an MFI zeolite synthesized by the sol-gel method (MFI SG).

Table 3. Relative crystallinity, MFI and MOR percentage of the synthesized samples and the seed. Sample nomenclature: $\mathrm{Na}$ is the $\mathrm{Na}_{2} \mathrm{O} / \mathrm{SiO}_{2}$ molar ratio, $\mathrm{H \#}$ is the $\mathrm{H}_{2} \mathrm{O} / \mathrm{SiO}_{2}$ molar ratio, $\mathrm{T}$ is the milling time and $\mathrm{S} \#$ is the milling speed.

\begin{tabular}{lccc}
\hline \multicolumn{1}{c}{ Material code } & $\begin{array}{c}\text { Crystallinity } \\
{[\%]}\end{array}$ & $\begin{array}{c}\text { MOR } \\
{[\%]}\end{array}$ & $\begin{array}{c}\text { MFI } \\
{[\%]}\end{array}$ \\
\hline \hline Seed & 100 & 7.5 & 92.5 \\
Z-Na0.2-H1.7-T5-S200 & 39.4 & 49.2 & 50.8 \\
Z-Na0.2-H2.0-T5-S200 & 40.9 & 40.6 & 59.4 \\
Z-Na0.2-H1.7-T5-S400 & 52.7 & 36.9 & 63.1 \\
Z-Na0.2-H2.0-T5-S400 & 53.5 & 38.3 & 61.7 \\
Z-Na0.2-H1.7-T16-S200 & 41.7 & 47.7 & 52.3 \\
Z-Na0.2-H2.0-T16-S200 & 48.2 & 39.6 & 60.4 \\
Z-Na0.2-H1.7-T16-S400 & 47.1 & 44.1 & 55.9 \\
Z-Na0.2-H2.0-T16-S400 & 52.5 & 34.3 & 65.7 \\
MFI S-G & 100 & 1.9 & 98.1 \\
\hline
\end{tabular}

Table 3 shows the relative crystallinity of each sample as calculated with equation S2. In general, all the samples from the materials synthesized by the mechanochemical method were less crystalline than both the MFI seed and the sol-gel MFI. This decrease in crystallinity could be attributed to the formation of less defined crystals in the synthesized samples compared to those of the seed, see Figure 7. On the other hand, the presence of MOR can also affect the percentage of relative crystallinity. ${ }^{61}$ In this sense, Gao et al. ${ }^{26}$ also found that a mechanically synthesized MOR zeolite had lower crystallinity than a commercial benchmark.

In what follows, a statistical analysis of the data in Table 3 will be featured. Figure 11 presents the results of the statistical analysis performed over the relative crystallinity of the mechanochemically synthesized materials in terms of an ANOVA table and of triple interaction plots. Supplementary plots for assessing the effects of the main and double interaction factors are presented in Figure S6. Within the defined sampling space, all the main factors of the experiment had a positive effect on the crystallinity percentage. The strength of these effects, ANOVA table in Figure 11, followed the trend: milling speed, $p$-value $=0.007>\mathrm{H}_{2} \mathrm{O} / \mathrm{SiO}_{2}, p$-value $=0.017>$ milling time, $p$-value $=0.084$. Concerning the double interaction factors, only those between the milling time and the milling speed and between the milling time and the $\mathrm{H}_{2} \mathrm{O} / \mathrm{SiO}_{2}$ molar ratio were considered statistically relevant and non-removable from the ANOVA model describing the data. However, the interpretation of these interactions is not straightforward. Indeed, the corresponding interaction plots, Figure S6, show that both the plots for the double interactions (milling time) $\times$ (milling speed) and (milling time $) \times\left(\mathrm{H}_{2} \mathrm{O} / \mathrm{SiO}_{2}\right.$ molar ratio) and their reciprocals (milling speed $) \times($ milling time) and $\left(\mathrm{H}_{2} \mathrm{O} / \mathrm{SiO}_{2}\right.$ molar ratio) $\times$ (milling time) had counter effects, meaning that their combination produced both synergistic and antagonistic effects over the response variable. According to $\mathrm{Wu}$ and Hamada $^{31}$ this kind of behavior reveals that the physical interpretation of these interactions is related either to some other underlying factors or to the presence of a quadratic dependency of the response variable on one or both of the considered input variables. ${ }^{31,62}$ On the other hand, the double interaction plots between the milling speed and the $\mathrm{H}_{2} \mathrm{O} / \mathrm{SiO}_{2}$ molar ratio were both synergistic. But, according to Loftus ${ }^{63}$ and Wagenmakers et al., ${ }^{64}$ the output of the interaction plots for this factor, Figure S6, indicates that it can be removed from the ANOVA model representing the data. This conclusion agrees with the highest $p$-value $(0.132)$ for this factor. Finally, the graphical assessment of the effect of the triple interaction factor for the experimental design, 


\begin{tabular}{ccccccccc}
\hline Factor & \multirow{2}{*}{ Effect } & Type of effect & SS $^{*}$ & $\begin{array}{c}\text { \%Contribution } \\
\text { SS }\end{array}$ & DF $^{* *}$ & MS $^{* * *}$ & F-ratio & p-value \\
\hline \hline T & 0.720 & Positive & 1.04 & 0.45 & 1 & 1.04 & 57.4 & 0.084 \\
$\mathrm{~S}$ & 8.895 & Positive & 158.20 & 69.19 & 1 & 158.24 & 8766.8 & 0.007 \\
$\mathrm{H}$ & 3.500 & Positive & 24.50 & 10.71 & 1 & 24.5 & 1357.3 & 0.017 \\
$\mathrm{TS}, \mathrm{ST}$ & -4.060 & Syn $/$ Ant & 33.00 & 14.41 & 1 & 32.97 & 1826.4 & 0.015 \\
$\mathrm{TH}, \mathrm{HT}$ & 2.405 & Syn/Ant & 11.60 & 5.06 & 1 & 11.57 & 640.9 & 0.025 \\
$\mathrm{SH}, \mathrm{HS}$ & -0.450 & Syn & 0.40 & 0.18 & 1 & 0.41 & 22.4 & 0.132 \\
TSH & -0.095 & N.A. & N.D. & N.D & 0 & N.D & N.D & N.D \\
Total & & & 228.70 & & 7 & 32.68 & & \\
Error & & & 0.02 & & 1 & 0.02 & & \\
\hline
\end{tabular}

*Sum of Squares

** Degrees of Freedom

*Synergistic

*Antagonistic

*** Mean Square

N.A: Not Applicable

N.D: Not Determined
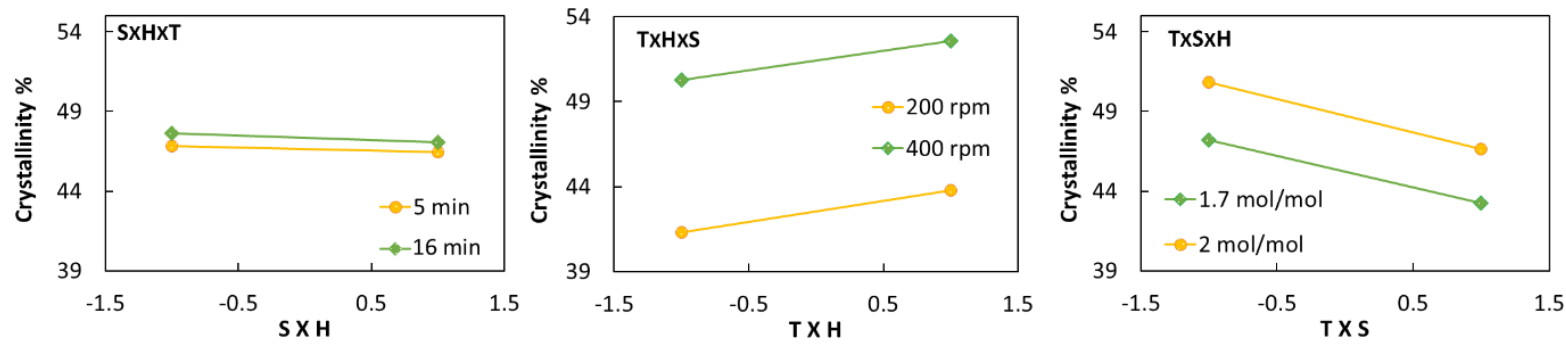

Figure 11. ANOVA table and interaction plots for assessing the effect of the triple factor of the synthesis variables on the crystallinity of the solvent-free seed-assisted synthesis of zeolites. In the nomenclature: $\mathrm{Na}$ and $\mathrm{H}$ correspond to the $\mathrm{Na}_{2} \mathrm{O} / \mathrm{SiO}_{2}$ and to the $\mathrm{H}_{2} \mathrm{O} / \mathrm{SiO}_{2}$ molar ratios, respectively, and $\mathrm{T}$ and $\mathrm{S}$ to the milling time and speed, respectively.

Figure 11, shows that this factor can also be removed from the ANOVA model for the data because all lines were parallel.

Based on these results, the response surface model represented in Equation 4 and Figure 12 was obtained. Confidence intervals for each of the parameters of the model and an analysis of its residuals are presented in Table $\mathbf{S 5}$ and Figure S7, respectively. From this model, the optimum for crystallinity at $\mathrm{H}_{2} \mathrm{O} / \mathrm{SiO}_{2}=2.0$ was found at 5 min of milling, and with a milling speed of $400 \mathrm{rpm}$.

The physical interpretation of this model must take into account how the interaction between milling time and speed impacted crystallinity. In this sense, Kho et al. ${ }^{65}$ proposed that the energy supplied to a material during ball milling has a non-linear dependency on the milling time and the milling speed, equation 5.
$\%$ Cryst $=47.00+4.45 \boldsymbol{S}+1.78 \boldsymbol{H}-2.03 \boldsymbol{T S}+1.20 \boldsymbol{T H}(4)$

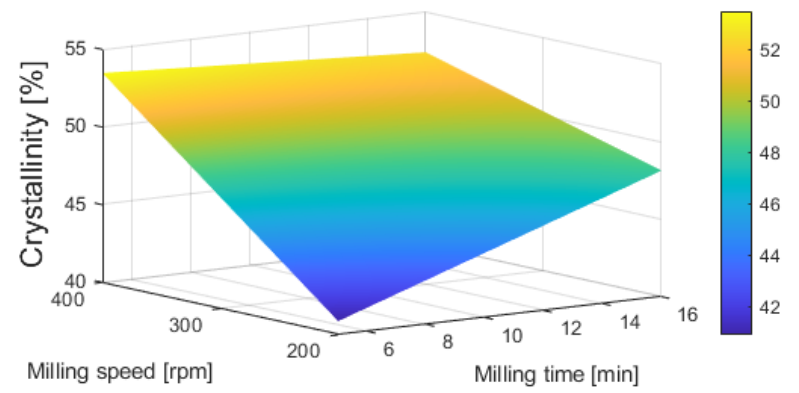

Figure 12. Response surface for the crystallinity of the samples with a ratio $\mathrm{H}_{2} \mathrm{O} / \mathrm{SiO}_{2}=2.0$. 


$$
E_{t}=\frac{N_{b}{ }^{2}}{2} K_{v} \omega_{p}{ }^{3} K_{a} K_{b}{ }^{2} \frac{m_{b}}{m_{p}} R_{p}{ }^{2} t
$$

Where,

$$
\begin{aligned}
& E_{t} \text { : Total energy per unit of } K_{b} \text { : Geometric parameter } \\
& N_{b} \text { : Number of milling balls } M_{b} \text { : Weight of each ball [kg] } \\
& K_{v} \text { : A parameter that } \quad m_{p}: \text { Weight of powder [g] } \\
& \text { depends on the ball's } \\
& \text { diameter and a kinetic } \\
& \text { factor } \\
& \omega_{p}: \text { Disk rotational speed } \\
& {[\mathrm{rpm}]=\text { milling speed }} \\
& R_{p}: \text { Distance between } \\
& \text { rotational axes }[\mathrm{m}] \\
& K_{a}: \text { Collision parameter } \\
& \mathrm{t} \text { : Milling time }[\mathrm{h}]
\end{aligned}
$$

Accordingly, the milling energy has a cubic dependence on the milling speed while it has a first order dependence on the milling time. This explains why the milling speed had the strongest effect on the crystallinity of the materials, see Figure 11. Considering this, Figure 13 plots the crystallinity of the synthesized materials as a function of the milling energy for the two levels of the $\mathrm{H}_{2} \mathrm{O} / \mathrm{SiO}_{2}$ molar ratio studied in the experimental design. The relative crystallinity of the materials reached a maximum value at a milling energy of ca. $1.1 \mathrm{~kJ} / \mathrm{g}$ which did not depend on the $\mathrm{H}_{2} \mathrm{O} / \mathrm{SiO}_{2}$ molar ratio. As reported in the literature, it is required that solid-state reactions occur between the initial silicon and aluminum precursors for the synthesis of zeolites without the use of solvents to be successful. ${ }^{17-19}$ The energy required for these reactions must be provided by the milling process, which would explain why an increase in the milling speed generated a positive effect on the crystallinity of the zeolites. Do and Friščić ${ }^{66}$ postulated that increasing the milling speed reduces the particle size of the seed, generating a greater amount of crystallization nuclei. Milling also reduces the particle size of the silicon and aluminum precursors and this in turn enhances the contact area between the reactants and with the zeolite seed hence favoring the reactions for the formation of the aluminosilicate precursors of the zeolite. Of course, as already commented, after surpassing certain milling conditions, amorphization of the seed may happen. ${ }^{48-51}$ This seems to be case for the zeolites milled at the $\mathrm{H}_{2} \mathrm{O} / \mathrm{SiO}_{2}=1.7$ molar ratio, Figure 13 . The positive effect of the $\mathrm{H}_{2} \mathrm{O} / \mathrm{SiO}_{2}$ ratio on the crystallinity of the zeolites could be associated with the fact that water can facilitate the hydrolysis and condensation of silica species in the solvent-less synthesis. ${ }^{16,67}$ Another possibility, which does not exclude the aforementioned, is that water can play the role of lubricant during milling. Therefore, lower amounts of water during milling may lead to harsher mechanical stresses.

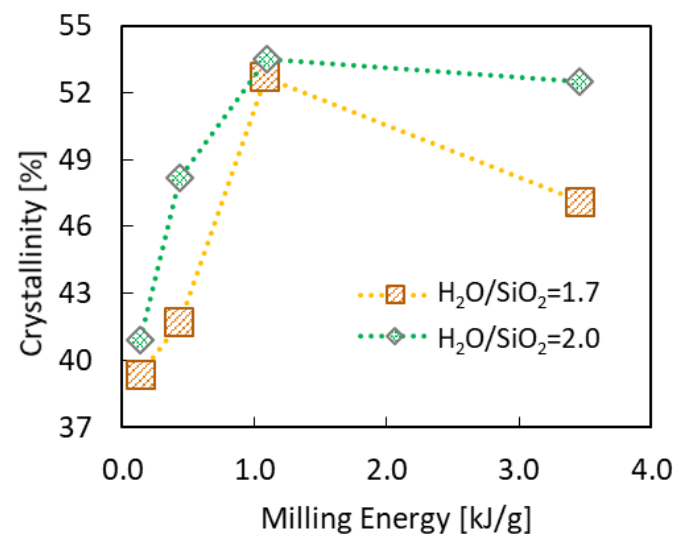

Figure 13. Crystallinity percentage of the synthesized zeolites as a function of the milling energy at different $\mathrm{H}_{2} \mathrm{O} / \mathrm{SiO}_{2}$ molar ratios.

The XRD analysis of the materials, Figure 10, revealed that the produced zeolites also contain crystals of MOR. It can be noticed that the seed also contained a certain fraction of MOR. Table 3 shows the relative percentage of the MFI phase for each material as estimated with equation S2. The statistical analysis of this data showed that all the factors studied within the implemented experimental design had weak effects over this response variable, Section S7, Figure S8. Therefore, the relative composition of the MFI and MOR phases for the zeolites synthesized via the mechanochemical method did not depend on the conditions used for ball milling. Indeed, the relative distribution of these two phases is controlled by the thermodynamics and kinetics of the hydrothermal stage. ${ }^{68-72}$

2.2.4 Porosity and surface area. $\chi-$ plots $^{42}$ for the argon adsorption-desorption isotherms based of a selected sample of Z-Na0.2-H2.0-T16-S400 and of the sol-gel MFI are presented in Figure 14. All the other isotherms are presented in the supporting information, section S4, Figure S2. While the sol-gel MFI, Figure 14b, showed the typical IUPAC Type I(a) adsorption isotherm of the microporous MFI, ${ }^{43,73}$ the zeolites synthesized by the mechanochemical method, Figure 14a and S4, showed more complex isotherms having two zones. The first zone, which goes from the low relative pressure region to a relative pressure of $\sim 0.75$, matched the Type $\mathrm{I}(\mathrm{a})$ 
isotherms expected for MFI, while the zone at higher relative pressures resembled a mixture between the IUPAC's Type II isotherm associated with either nonporous or macroporous solids that are not fully wetted by the adsorbate ${ }^{74,75}$ and the Type IV isotherm associated with a mesoporous solid. ${ }^{73}$ For the latter, one may notice that the isotherm, Figure 14a, showed a narrow hysteresis closing at a relative pressure of $\sim 0.99$. As commented earlier, Section 2.2.1, the mechanochemically synthesized zeolites are composed of tight irregularly shaped agglomerates of ca. $1.0 \mu \mathrm{m}$ zeolitic crystals from which adsorption isotherms such as those presented Figure 14a and S4 may be expected since the shape of the high relative pressure of the isotherm is normally produced by narrow interparticle voids. ${ }^{76}$ These interparticle spaces were not found for the solgel MFI which showed well-defined crystals that were larger than those of the commercial MFI, see Figure 7.
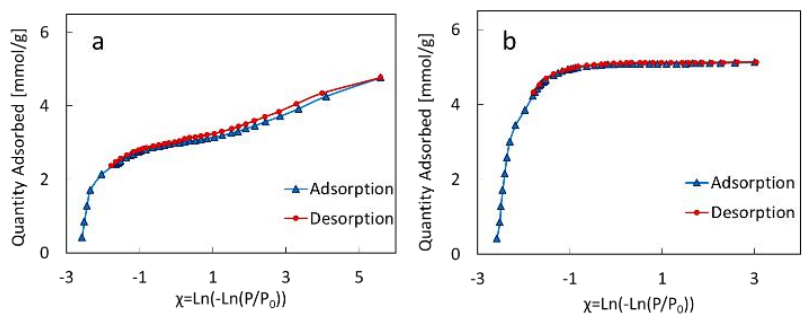

some selected samples: a) Z-Na0.2-H2.0 -T16-S400 and b) the MFI zeolite synthesized by the sol-gel method.

The estimated textural properties of the mechanochemically synthesized zeolites as well as those of the benchmark zeolites and the sol-gel MFI, are presented in Table 4. In general, all the zeolites synthesized with a $\mathrm{Na}_{2} \mathrm{O} / \mathrm{SiO}_{2}=0.2$ molar ratio had an average micropore size distribution similar to the one of the benchmark zeolites and to the sol-gel MFI. However, both the estimated total pore volume and the BET surface area of the samples of the zeolites synthesized by the mechanochemical method were always lower, $\sim 49 \%$ \& $\sim 50 \%$ in average, respectively. A statistical analysis of the data in Table 4 is presented in the Supporting Information, Figures S11, S12, S14, S15 and S17. In the case of the microporous surface area, none of the factors studied during ball milling had effects reaching statistical relevance at a $95 \%$ confidence level. Therefore, as in the case of the relative distribution of the MFI and MOR phases of the produced materials, it can be considered that the conditions used during ball milling did not affect this response variable.

Figures 15 and S17 present the statistical analysis performed for data of the external surface area of the materials. Within the defined sampling space, all the main factors of the experiment had a positive effect

Figure 14. Argon adsorption-desorption isotherms of

Table 4. Textural properties of the zeolites synthesized with a $\mathrm{H}_{2} \mathrm{O} / \mathrm{SiO}_{2}=0.2$ molar ratio, the MFI seed, a commercial MOR (CBV 21A) and a MFI synthesized by a sol-gel method (MFI S-G). Sample nomenclature: Na\# is the $\mathrm{Na}_{2} \mathrm{O} / \mathrm{SiO}_{2}$ molar ratio, $\mathrm{H \#}$ is the $\mathrm{H}_{2} \mathrm{O} / \mathrm{SiO}_{2}$ molar ratio, $\mathrm{T}$ is the milling time and $\mathrm{S \#}$ is the milling speed.

\begin{tabular}{lccccccc}
\hline \multicolumn{1}{c}{ Material code } & $\begin{array}{c}\mathrm{S}_{\text {BET }} \\
{\left[\mathrm{m}^{2} / \mathrm{g}\right]}\end{array}$ & $\begin{array}{c}\mathrm{S}_{\text {micro }} \\
{\left[\mathrm{m}^{2} / \mathrm{g}\right]}\end{array}$ & $\begin{array}{c}\mathrm{S}_{\text {ext }} \\
{\left[\mathrm{m}^{2} / \mathrm{g}\right]}\end{array}$ & $\begin{array}{c}\mathrm{V}_{\text {total }} \\
{\left[\mathrm{cm}^{3} / \mathrm{g}\right]}\end{array}$ & $\begin{array}{c}\mathrm{V}_{\text {micro }} \\
{\left[\mathrm{cm}^{3} / \mathrm{g}\right]}\end{array}$ & $\begin{array}{c}\text { Average pore } \\
\text { width [nm }]\end{array}$ & C $_{\text {BET }}$ \\
\hline \hline Seed & 407 & 369 & 38 & 0.192 & 0.129 & 0.58 & 2273 \\
Z-Na0.2-H1.7-T5-S200 & 148 & 138 & 10 & 0.056 & 0.047 & 0.56 & 2306 \\
Z-Na0.2-H2.0-T5-S200 & 174 & 161 & 13 & 0.077 & 0.056 & 0.56 & 2601 \\
Z-Na0.2-H1.7-T5-S400 & 221 & 195 & 26 & 0.120 & 0.069 & 0.57 & 1872 \\
Z-Na0.2-H2.0-T5-S400 & 218 & 194 & 24 & 0.108 & 0.068 & 0.57 & 2109 \\
Z-Na0.2-H1.7-T16-S200 & 194 & 184 & 10 & 0.082 & 0.064 & 0.59 & 2517 \\
Z-Na0.2-H2.0-T16-S200 & 201 & 185 & 16 & 0.087 & 0.065 & 0.56 & 2598 \\
Z-Na0.2-H1.7-T16-S400 & 222 & 189 & 33 & 0.122 & 0.062 & 0.56 & 2087 \\
Z-Na0.2-H2.0-T16-S400 & 225 & 190 & 35 & 0.127 & 0.067 & 0.56 & 1836 \\
MFI S-G & 410 & 388 & 22 & 0.161 & 0.093 & 0.57 & 3168 \\
MOR & 497 & 439 & 58 & 0.263 & 0.154 & 0.60 & 4769 \\
\hline
\end{tabular}




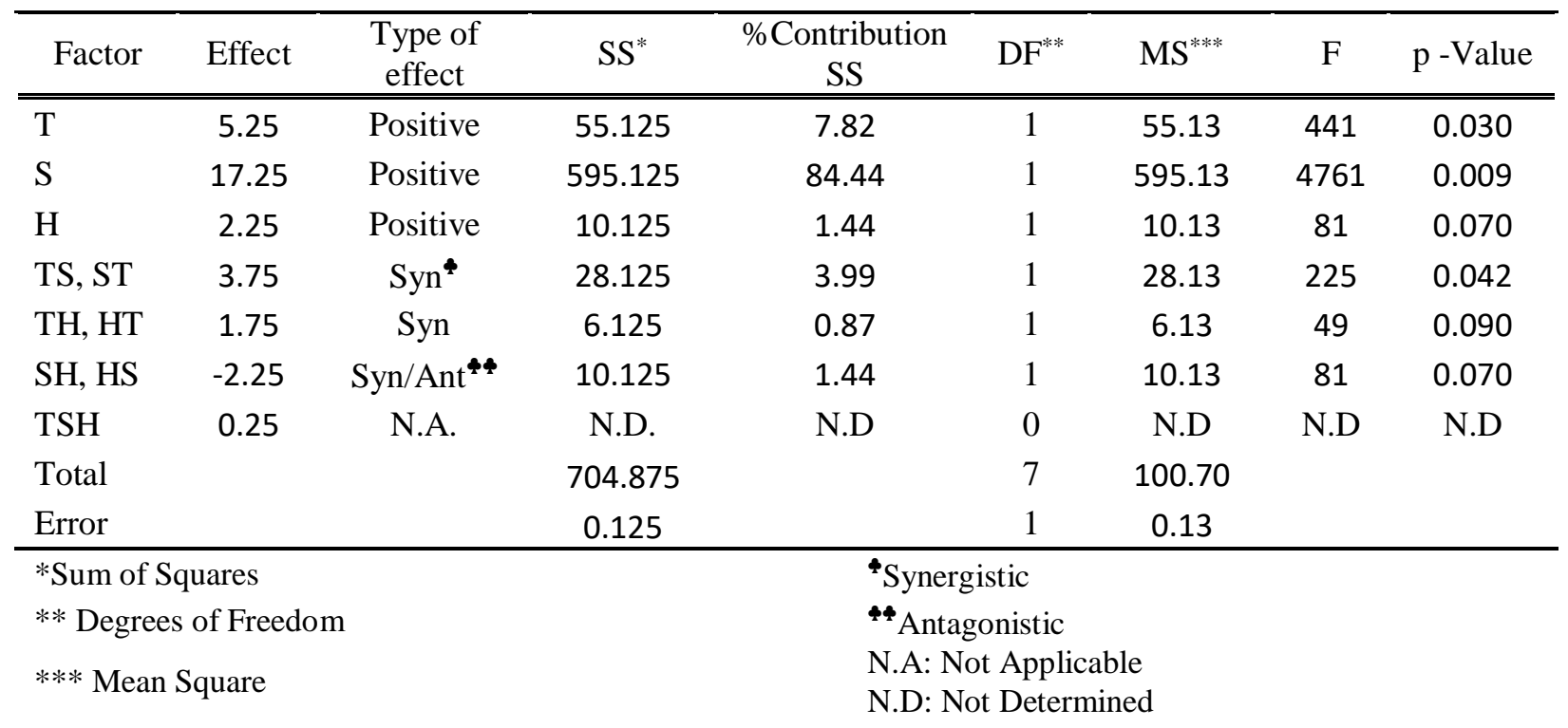
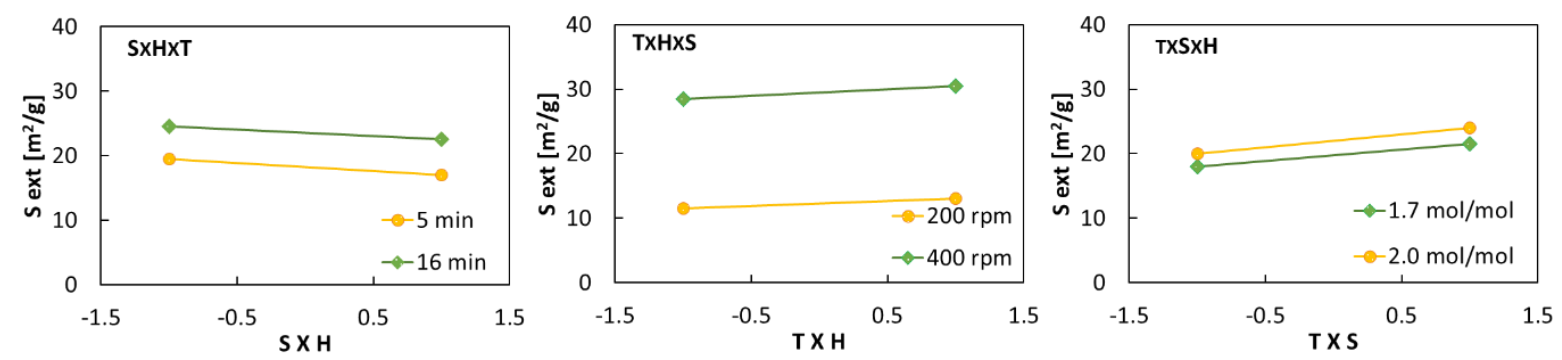

Figure 15. ANOVA table and interaction plots for assessing the effect of the triple factor of the synthesis variables on the external surface area of the solvent-free seed-assisted synthesis of zeolites. In the nomenclature: $\mathrm{Na}$ and $\mathrm{H}$ correspond to the $\mathrm{Na}_{2} \mathrm{O} / \mathrm{SiO}_{2}$ and to the $\mathrm{H}_{2} \mathrm{O} / \mathrm{SiO}_{2}$ molar ratios, respectively, and $\mathrm{T}$ and $\mathrm{S}$ to the milling time and speed, respectively.

on the external surface area. For a 95\% confidence threshold, the milling speed and milling time were statistically significant. Concerning double interactions, only the (milling time) $\times$ (milling speed) interaction was statistically significant. On the other hand, the triple interaction can be removed from the ANOVA model for the data. In general, the milling speed and time were the factors that most affected the external surface because the increase in milling energy produced smaller and ill-defined crystals that formed agglomerates, Figure 7. The external area of the materials corresponds to the spaces between the small agglomerated crystals. ${ }^{61}$ Therefore, it is reflected in the formation of a hysteresis loop in the adsorption isotherms at high relative pressures, Figure 14. It can be noticed that such hysteresis was not present for the sol-gel MFI.

2.2.5 Acidity of the protonated materials. Figure 16 shows the pyridine adsorption spectra of two selected samples of the protonated zeolites; namely, Z-Na0.2-H1.7-T5-S400 and Z-Na0.2-H2.0-T5-S400, and of the protonated benchmark zeolites. All materials showed the typical peaks associated with pyridine adsorption at Brønsted, $1455 \mathrm{~cm}^{-1}$, Lewis, $1500 \mathrm{~cm}^{-1}$, and overlapping of Brønsted and Lewis sites, $1545 \mathrm{~cm}^{-1} \cdot{ }^{77}$

Considering the recorded spectra, Table 5 summarizes the quantification of the acidity of the materials as estimated from equations S4 \& S5. In general, the mechanochemical zeolites had a higher concentration of Lewis acid sites than the commercial MFI. The reason for this is most likely the higher concentration of aluminum for the former, Table 2. Aluminum makes Lewis acid sites. ${ }^{78,79}$ On the other hand, except for the sample Z-Na0.2-H2.0-T16S400, i.e. the one milled with the highest $\mathrm{H}_{2} \mathrm{O} / \mathrm{SiO}_{2}$ molar ratio, all the mechanochemical zeolites had a lower concentration of Brønsted acid sites than the commercial MFI. A statistical assessment of the effects of the experimental factors studied during ball milling over the Brønsted acidity of the materials, Figures S18 and S19, showed that none of the former 
were as strong as to be considered statistically meaningful at a confidence level of $95 \%$. This result was consistent with that obtained by SEM-EDS, Section 2.2.1, where the synthesized samples

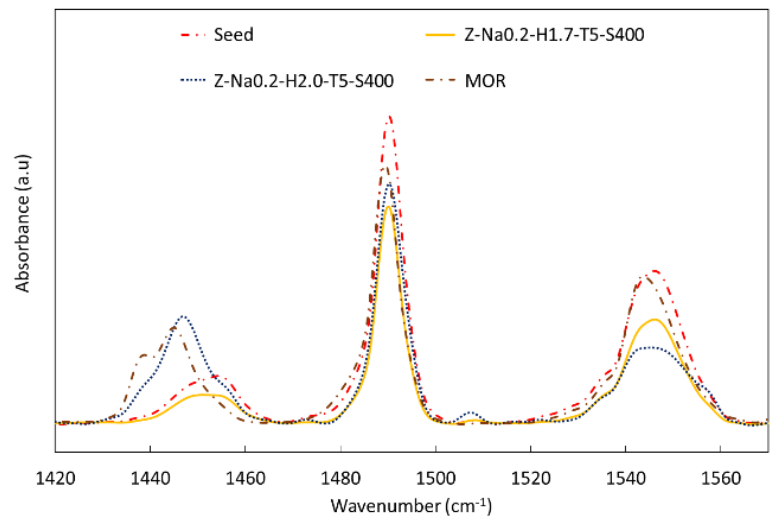

Figure 16. FTIR spectra for pyridine adsorption for two selected samples from the protonated zeolites synthesized via the mechanochemical method, the protonated seed zeolite, and the protonated commercial MOR (CBV 21A). The bands at $1545 \mathrm{~cm}^{-1}$ and $1455 \mathrm{~cm}^{-1}$ correspond to pyridine adsorption on Brønsted and Lewis sites, respectively. The band at $1491 \mathrm{~cm}^{-1}$ corresponds to an overlap of the signals from pyridine adsorbed on both the Brønsted and the Lewis sites, and the band at $1445 \mathrm{~cm}^{-1}$ corresponds to physically adsorbed pyridine. ${ }^{77}$

presented a $\mathrm{Si} / \mathrm{Al}$ ratio that did not depend on the milling conditions and was approximately constant. Therefore, the same effects can be considered for the concentration of acid sites because this property is related to the concentration of aluminum in the zeolite. ${ }^{54}$ This conclusion did not imply that the synthesized materials had the same acidity. Indeed, Table 5 shows that the synthesized zeolites had different acidities. What happened with the statistical analysis was that its power is rather limited when concerning the detection of effects for a process such as protonation that comes at a much further and independent stage.

Despite the limitations of the statistical analysis, it was possible to detect an effect from the triple interaction factor over the concentration of Lewis sites, Section S7, Figure S20. This suggests that the concentration of Lewis sites may be affected by certain combinations of the $\mathrm{H}_{2} \mathrm{O} / \mathrm{SiO}_{2}$ molar ratio, and of the milling time and speed. This effect was actually consistent with the fact that the synthesized samples presented a higher amount of Lewis sites than the seed, since they presented a lower $\mathrm{Si} / \mathrm{Al}$ ratio, Table 2. In this regard, lower $\mathrm{Si} / \mathrm{Al}$ ratios in zeolites are typically due to the so-called extra-framework aluminum which contribute Lewis acidity to the materials. ${ }^{78,80,81}$

2.2.6 Catalytic behavior. Table 6 shows the catalytic results for the alkylation of phenol with tertbutanol over the studied materials. The yield to each product is provided in Section S11, Table S11. Under the implemented reaction conditions, the main reaction product for all catalysts was tert-butyl phenyl ether. The mono-alkylated products that were found in a higher proportion were 2-tert-butyl-phenol and

Table 5. Concentration of total acid sites and of the Brønsted and Lewis sites for the synthesized samples and the seed zeolite, according to pyridine adsorption test. [mmol/g]. Sample nomenclature: Na\# is the $\mathrm{Na}_{2} \mathrm{O} / \mathrm{SiO}_{2}$ molar ratio, $\mathrm{H \#}$ is the $\mathrm{H}_{2} \mathrm{O} / \mathrm{SiO}_{2}$ molar ratio, $\mathrm{T}$ is the milling time and $\mathrm{S \#}$ is the milling speed.

\begin{tabular}{lcccc}
\hline \multirow{2}{*}{\multicolumn{1}{c}{ Material code }} & \multicolumn{2}{c}{ Acid sites concentration $[\mathrm{mmol} / \mathrm{g}]$} & \multirow{2}{*}{$\begin{array}{c}\text { Acid sites } \\
\text { density } \\
{\left[\mu \mathrm{mol} / \mathrm{m}^{2}\right]}\end{array}$} \\
\cline { 2 - 4 } & Total & Brønsted & Lewis & 1.74 \\
Seed & 0.71 & 0.65 & 0.06 & 2.50 \\
Z-Na0.2-H1.7-T5-S200 & 0.37 & 0.20 & 0.17 & 1.78 \\
Z-Na0.2-H2.0-T5-S200 & 0.31 & 0.07 & 0.24 & 2.22 \\
Z-Na0.2-H1.7-T5-S400 & 0.49 & 0.45 & 0.04 & 2.98 \\
Z-Na0.2-H2.0-T5-S400 & 0.65 & 0.36 & 0.29 & 2.47 \\
Z-Na0.2-H1.7-T16-S200 & 0.48 & 0.33 & 0.15 & 2.39 \\
Z-Na0.2-H2.0-T16-S200 & 0.48 & 0.31 & 0.17 & 2.88 \\
Z-Na0.2-H1.7-T16-S400 & 0.64 & 0.36 & 0.28 & 3.11 \\
Z-Na0.2-H2.0-T16-S400 & 0.70 & 0.64 & 0.06 & 2.49 \\
MOR & 1.24 & 1.17 & 0.07 & \\
\hline
\end{tabular}


4-tert-butyl-phenol. Their formation can be attributed to the rearrangement of tert-butyl phenyl ether and to the direct alkylation of phenol. 3-tert-butyl-phenol presented the lowest selectivity compared to the other mono-alkylated products, and its production could be associated to the isomerization of 4-tert-butyl-phenol and 2-tert-butyl-phenol. Table 6 also shows the formation of 2,4-di-tert-butyl phenol, the production of which could be associated to the di-alkylation of 2tert-butyl-phenol and 4-tert-butyl-phenol. Additionally, we observed the presence of bubbles in the samples taken after the reaction tests. These bubbles were confirmed to be isobutylene produced during the reaction. Isobutylene is the product of the dehydration of tert-butyl alcohol.

In general, the statistical analysis of the effects of factors intervening in the milling stage of the synthesis of the materials did not detect significant effects for any of them over the catalytic behavior, Supporting Information, Section S7, Figures S22, S25 and S27. As commented before, it would be very hard for this kind of statistical test to detect effects for a much further independent stage process.

A direct correlation was found between the concentration of Brønsted acid sites and the conversion of both phenol and tert-butyl alcohol, Figure 17a. Conversely, no apparent correlation was found between the number of Lewis acid sites and the conversion of any of the reactants. The results in Table 6 show that the conversion of tert-butyl alcohol was ca. tenfold the one of phenol, indicating that tertbutyl alcohol is preferentially adsorbed over the acid sites and converts into isobutylene. It seems that the preferential adsorption of tert-butyl alcohol saturates the catalytic surface hence restricting the adsorption of phenol. On the other hand, Figure 17b shows a direct correlation between the density of acid sites and the conversion of both phenol and tert-butyl alcohol, this indicates that the increase in conversion was not only due to the amount of acid sites present in the zeolites, but also to the proximity between them.

As observed in Table 6, tert-butyl phenyl ether was the main product of the reaction, which could be attributed to the low activation energy required for its formation. Indeed, this product can be produced in homogeneous phase without the aid of a catalyst, ${ }^{41,82,83}$ which can be evidenced in the first entry of Table 6. Figure 18a shows that the selectivity of tert-butyl phenyl ether has an inverse correlation with both phenol and tert-butyl alcohol conversion. Jansang et al. ${ }^{83}$ found that the O-tertbutylated product, tert-butyl phenyl ether, is a kinetically primary product, while the C-tertbutylated product is the most thermodynamically stable product. Therefore, by increasing the

Table 6. Conversion and selectivity of the phenol alkylation with tert-butyl alcohol for each synthesized zeolite and for the seed. Abbreviations: tert-butyl alcohol (TBA), isobutylene (IBE), tert-butyl phenyl ether (t-BPE), 2-tert-butyl-phenol (2TBP), 4-tert-butyl-phenol (4-TBP), 3-tert-butyl-phenol (3-TBP) and 2,4-di-tert-butyl phenol (2,4 DTBP). † Maximum yield of IBE based on the TBA conversion.

\begin{tabular}{|c|c|c|c|c|c|c|c|c|}
\hline \multirow[b]{2}{*}{ Material code } & \multirow{2}{*}{$\begin{array}{c}\mathrm{X}_{\text {phenol }} \\
{[\%]}\end{array}$} & \multirow{2}{*}{$\begin{array}{c}\mathrm{X}_{\mathrm{TBA}} \\
{[\%]}\end{array}$} & \multicolumn{5}{|c|}{ Selectivity [\%] } & \multirow{2}{*}{$\begin{array}{c}\text { Yield } \\
\text { of } \\
\text { IBE } \dagger \\
{[\%]}\end{array}$} \\
\hline & & & 2-ТBP & 4-TBP & 3-ТВP & $\begin{array}{c}2,4- \\
\text { DTBP }\end{array}$ & $\mathrm{t}-\mathrm{BPE}$ & \\
\hline Without catalyst & 0.52 & 0.48 & 0.00 & 0.00 & 0.00 & 0.00 & 100.00 & 0.03 \\
\hline Seed & 5.32 & 40.46 & 9.31 & 9.13 & 0.72 & 0.12 & 80.72 & 35.12 \\
\hline Z-Na0.2-H1.7-T5-S200 & 2.21 & 27.14 & 2.87 & 4.21 & 0.21 & 0.06 & 92.65 & 24.93 \\
\hline $\mathrm{Z}-\mathrm{Na} 0.2-\mathrm{H} 2.0-\mathrm{T} 5-\mathrm{S} 200$ & 0.90 & 20.39 & 2.55 & 2.01 & 0.10 & 0.03 & 95.31 & 19.49 \\
\hline Z-Na0.2-H1.7-T5-S400 & 4.06 & 38.89 & 4.53 & 4.54 & 0.29 & 0.05 & 90.59 & 34.83 \\
\hline $\mathrm{Z}-\mathrm{Na} 0.2-\mathrm{H} 2.0-\mathrm{T} 5-\mathrm{S} 400$ & 4.77 & 38.84 & 7.23 & 5.87 & 0.50 & 0.08 & 86.32 & 34.07 \\
\hline Z-Na0.2-H1.7-T16-S200 & 2.90 & 32.9 & 3.76 & 4.46 & 0.26 & 0.04 & 91.48 & 30.00 \\
\hline $\mathrm{Z}-\mathrm{Na} 0.2-\mathrm{H} 2.0-\mathrm{T} 16-\mathrm{S} 200$ & 2.43 & 27.49 & 2.56 & 2.06 & 0.16 & 0.04 & 95.18 & 25.06 \\
\hline Z-Na0.2-H1.7-T16-S400 & 4.80 & 51.89 & 19.11 & 13.71 & 1.13 & 0.42 & 65.63 & 47.08 \\
\hline Z-Na0.2-H2.0-T16-S400 & 5.64 & 40.15 & 7.93 & 8.32 & 0.63 & 0.13 & 82.99 & 34.50 \\
\hline MOR & 16.70 & 58.64 & 19.28 & 63.60 & 3.15 & 0.79 & 13.18 & 41.80 \\
\hline
\end{tabular}


conversion of both reactants, the formation of the Ctert-butylated products is favored, Figure 19. On the other hand, the low production of di-alkylated compounds and the fact that a tri-alkylated compound was not found could be due to shape selectivity phenomena restricting the production of bulky molecules. $^{82,84}$ In the case of MOR, a higher conversion of phenol was obtained due to its higher concentration of acid sites, see Table 5. Furthermore, due to the increase in acidity, the selectivity towards alkylated compounds also increased.
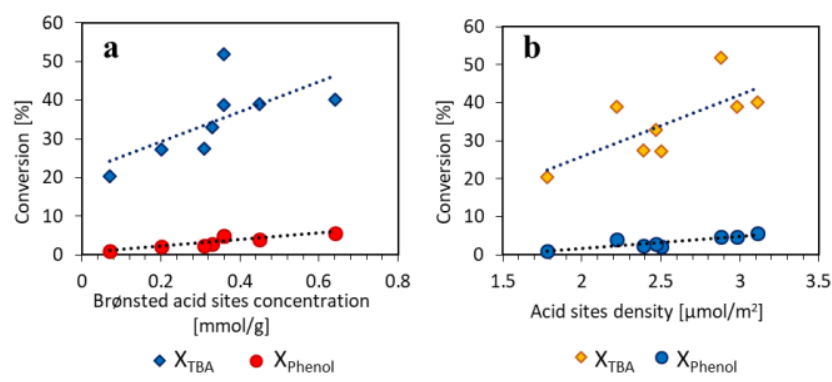

Figure 17. Correlation between phenol and tert-butyl alcohol (TBA) conversion in the phenol alkylation reaction and (a) the Brønsted acid sites concentration and (b) the acid sites density of the zeolites synthesized by the seedassisted mechanochemical route.
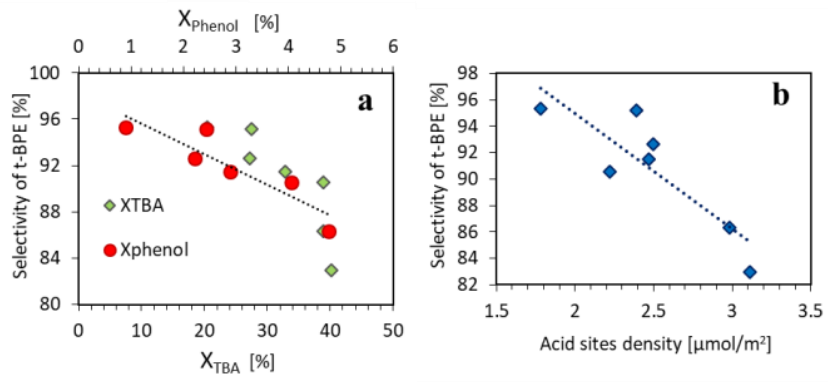

Figure 18. Correlation between phenol conversion, tertbutyl alcohol conversion and the selectivity of tert-butyl phenyl (t-BPE) (a) and between the acid sites density and the selectivity of tert-butyl phenyl ether (b).

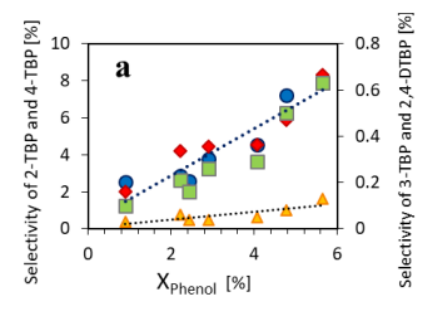

○2-ТВP 4-TBP $\square 3$-TBP $\triangle 2,4$-DTBP

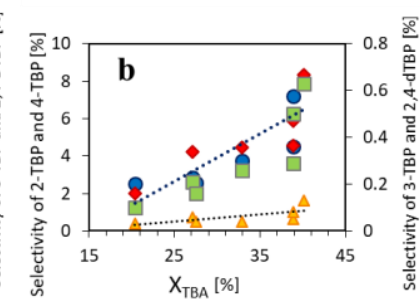

०2-ТВP $\bullet$ 4-ТВP घ3-ТВP $\triangle 2,4-$ DTBP
Figure 19. Correlation between the selectivity of the Calkylated products and both (a) the phenol conversion and (b) the tert-butyl alcohol conversion in the phenol alkylation reaction.
Nie et al. ${ }^{85}$ proposed that the alkylation of phenol could be carried out over Brønsted acid sites through two mechanisms; namely, a stepwise and a concerted mechanism. The first involves the generation of a tert-butyl carbenium ion due to dehydration of tertbutyl alcohol, and then this carbenium ion reacts with the co-adsorbed phenol to form the tert-butylation product. The carbenium ion can also deprotonate to form isobutylene. Meanwhile, the concerted pathway may proceed with the initial co-adsorption of phenol and tert-butyl alcohol followed by tert-butylation of phenol directly without formation of tert-butyl carbenium. Zhao et al. ${ }^{86}$ studied the alkylation of phenol on zeolites with in situ solid-state NMR spectroscopy and concluded that the stepwise mechanism is favored under real conditions of reaction. According to the results of this work, it seems that the stepwise reaction path was also favored over the concerted path. One of the reasons to think so was the extensive production of isobutylene during the reaction, Table 6. Considering our observations, we further propose that the reaction may follow a Langmuir-Hinshelwood reaction pathway like the one shown in Scheme 2. This scheme illustrates the competition between phenol and tert-butyl alcohol for the acid sites of the zeolite. As mentioned earlier, tert-butanol was preferentially adsorbed on the catalyst surface. The adsorption of tert-butyl alcohol is favored by shape-selectivity. ${ }^{87,88}$ On the other hand, phenol adsorption could also be restricted by the presence of water molecules produced during the dehydration of tert-butyl alcohol. ${ }^{89,90}$ Furthermore, it has been shown that aluminum-rich zeolites, such as the ones featured herein, favor the adsorption of water molecules due to their affinity with aluminum atoms ${ }^{89-91}$ Figure 20 shows that there was a direct relationship between the conversion of phenol and that of tert-butyl alcohol, that may also support the proposed mechanism because an increase in the conversion of followed from an increase in the conversion of tert-butyl alcohol. This may have released active sites hence allowing phenol to (re)adsorb and react.

Another finding consistent with the pathway proposed in Scheme 2 was the correlation found between the conversion of both reactants and the density of acid sites, Figure 17b. Indeed, according to the featured proposal, the adsorbed phenol must be close to the carbenium ion in order to generate the alkylated product. Since the reaction can be carried out by the stepwise mechanism, a greater proximity 
between the sites can favor the formation of C-tertbutylated products and the di-alkylated product, Figure 20b. Finally, the increase in selectivity towards $\mathrm{C}$-alkylated products was also reflected in a decrease in selectivity towards tert-butyl phenyl ether, Figure 18b, possibly due to its transformation into more stable products such as C-alkylated ones. ${ }^{83}$

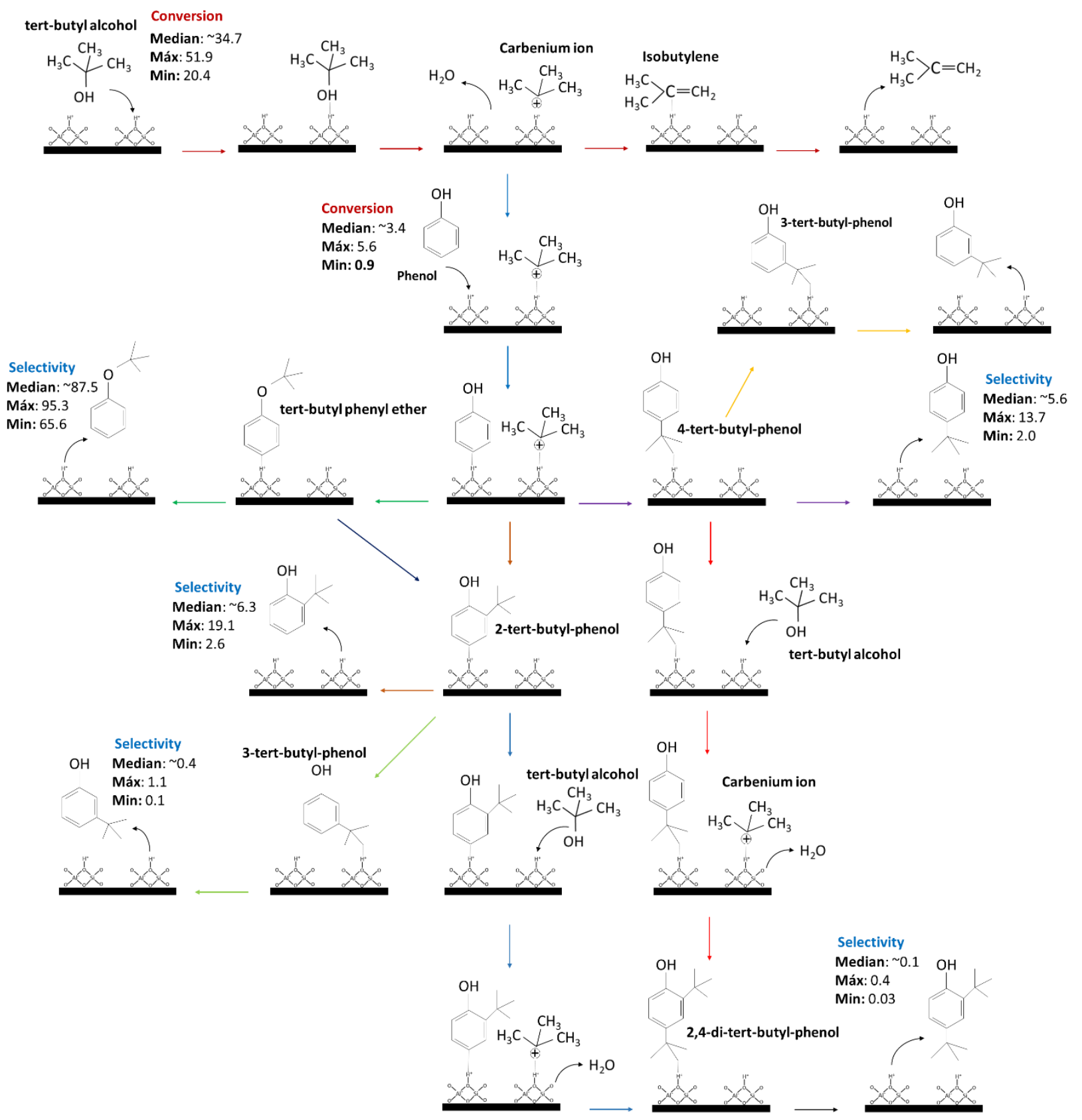

Scheme 2. Proposed Langmuir Hinshelwood reaction pathway for the alkylation of phenol with tert-butyl alcohol. 

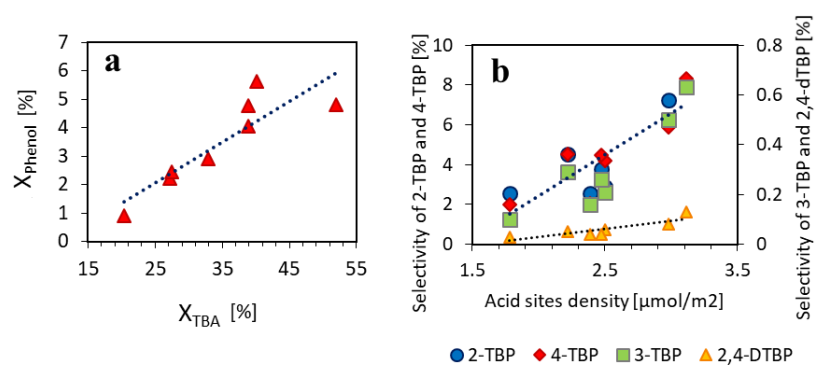

Figure 20. Correlation between the tert-butyl alcohol (TBA) conversion and the phenol conversion (a) and between the selectivity of the C-alkylated products and the acid sites density (b) in the phenol alkylation reaction for the synthesized zeolites.

3. General summary. Table 7 summarizes the effects of the factors associated with the $\mathrm{Na}_{2} \mathrm{O} / \mathrm{SiO}_{2}$ and $\mathrm{H}_{2} \mathrm{O} / \mathrm{SiO}_{2}$ molar ratios and the milling time and speed over the key properties of zeolites synthesized via a mechanochemical route assisted with a commercial MFI seed and in the absence of a solvent. The table codifies whether the effects were statistically significant at a 95\% confidence level and if whether they were positive, negative and synergistic or antagonistic in the case of interactions. The following remarks can be made. (i) the $\mathrm{Na}_{2} \mathrm{O} / \mathrm{SiO}_{2}$ mole ratio had a key role on the synthesis.
Properties such as the recovery percentage, crystallinity, the relative MFI/MOR percentage, morphology, and surface micropore area were strongly affected by this input variable. Furthermore, within the investigated sampling space, the synthesis was found to be viable only when the $\mathrm{Na}_{2} \mathrm{O} / \mathrm{SiO}_{2}$ mole ratio was 0.2 . (ii) $\mathrm{The} \mathrm{H}_{2} \mathrm{O} / \mathrm{SiO}_{2}$ mole ratio only had a strong positive influence on the crystallinity of the materials. The variable had a positive effect on the textural properties and over the concentration of Brønsted acid sites, but its effect was rather weak. (iii) The milling time had its strongest positive effect over the external surface area of the materials. One may recall that the external surface area was correlated to the presence of amorphous agglomerated particles mixed with zeolitic crystals. The milling time had weaker positive effects over the other measured properties except over the recovery percentage, the relative MFI/MOR percentage, and over the Lewis acid sites percentage. (iv) The milling speed had strong positive effects over the crystallinity, the external surface area, and over the conversion of phenol. The variable also had positive but weaker effects over the other measured properties except over the recovery percentage. (v) The double interaction, i.e. non-additivity terms, between the

Table 7. Summary of the effect of the synthesis variables and their combinations on key physicochemical properties of zeolites synthesized by a seed-assisted mechanochemical pathway. Sample nomenclature: $\mathrm{Na}$ is the $\mathrm{Na}_{2} \mathrm{O} / \mathrm{SiO}_{2}$ molar ratio, $\mathrm{T}$ is the milling time, $\mathrm{S}$ is the milling speed and $\mathrm{H}$ is the $\mathrm{H}_{2} \mathrm{O} / \mathrm{SiO}_{2}$ molar ratio.

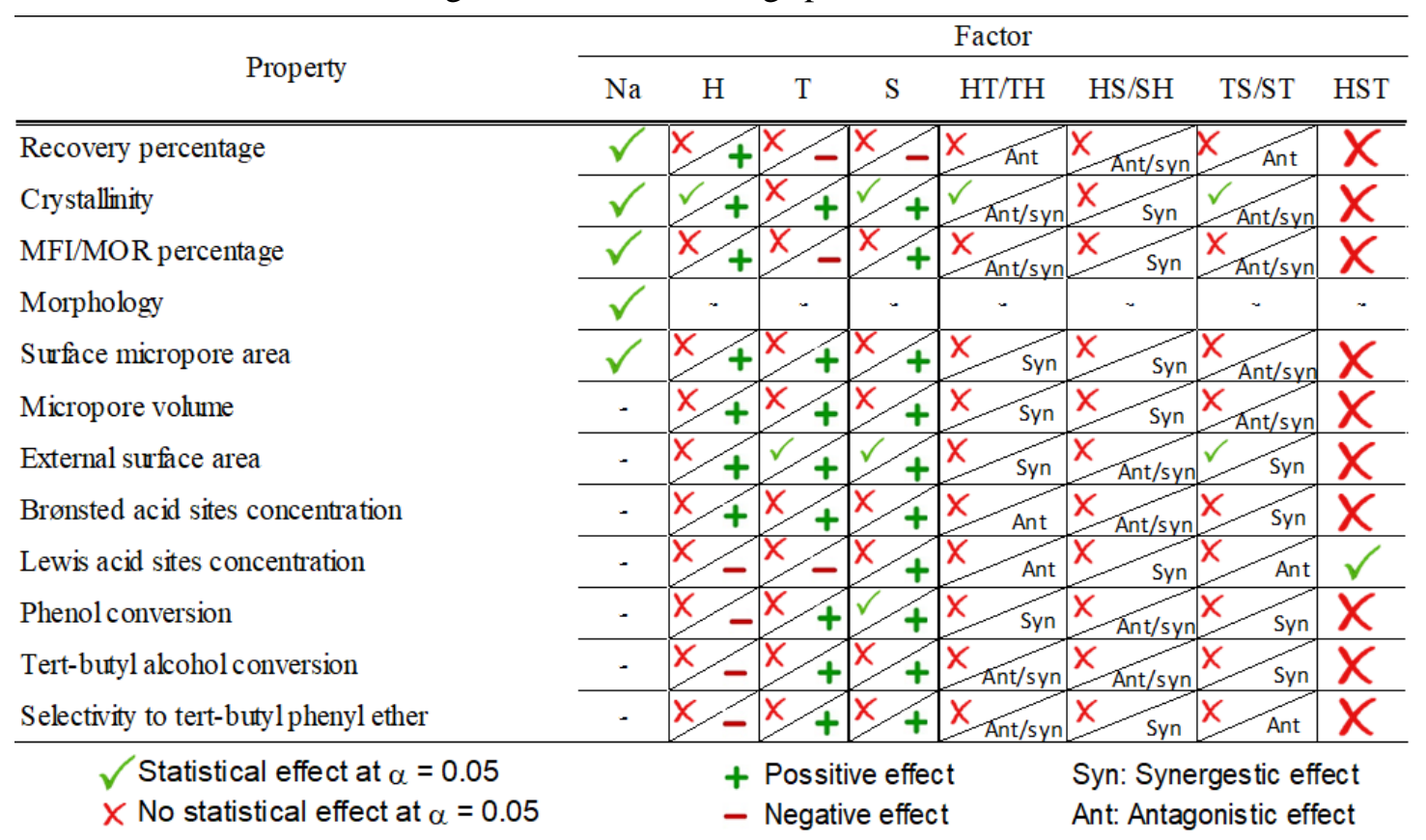


input variables of the experiment had mostly statistically negligible effects over the assessed properties except for the interaction between the $\mathrm{H}_{2} \mathrm{O} / \mathrm{SiO}_{2}$ mole ratio and the milling time and of the milling time and the milling speed over the crystallinity. The latter had also a strong and synergistic effect over the external surface area. As demonstrated in the paper, these interactions arose due to the non-linear dependence of the milling energy on the milling time and speed. (vi) Concerning triple interactions, only the one between the $\mathrm{H}_{2} \mathrm{O} / \mathrm{SiO}_{2}$ mole ratio and the milling speed and time had an effect over the concentration of Lewis acid sites.

Conclusions. This contribution investigated how the factors associated with the $\mathrm{Na}_{2} \mathrm{O} / \mathrm{SiO}_{2}$ and $\mathrm{H}_{2} \mathrm{O} / \mathrm{SiO}_{2}$ molar ratios and the milling time and speed used during the ball milling stage of the mechanochemical synthesis of MFI assisted by a parent MFI seed and free of solvent impact the characteristics and catalytic performance in the alkylation of phenol with tertbutyl alcohol of the thus produced zeolites. Results showed that the $\mathrm{Na}_{2} \mathrm{O} / \mathrm{SiO}_{2}$ molar ratio is key for making the synthesis either viable or unviable economically. Also, this variable may lead to the preferential production of MOR instead of MFI. On the other hand, the milling time and speed and their interactions drove the textural properties and the concentration of Lewis acid sites of MFI. These effects were rationalized by considering that: (i) sodium can act as a structure directing agent during the synthesis while promoting the incorporation of aluminum to its structure. (ii) The milling time and speed are non-linearly correlated to the milling energy required for producing the chemistry leading to the aluminosilicate precursors that crystallize during the hydrothermal stage of the process. Overall, all the zeolites synthesized by the mechanochemical route were less crystalline than both the MFI used as seed and an MFI synthesized by sol-gel. This was associated to the formation of amorphous agglomerates around the zeolitic crystals. It was established that these agglomerates contributed to the formation of a certain fraction of mesopores and to the Lewis acidity of the zeolites. Finally, the catalytic behavior of the mechanochemical MFI zeolites in the studied reaction was found to be linearly and positively correlated with both the concentration of Brønsted of sites and with the density of acid sites. The catalytic tendencies were consistent with the proposal of a stepwise Langmuir-Hinshelwood mechanism for the alkylation of phenol with tert-butyl alcohol.

\section{Associated content}

The Supporting Information is available free of charge. It includes:

Experimental section, control experiment without the use of seed, reactants used to synthesize each sample, characterization of Ar physisorption, ATR spectra, SEM images, and XRD patterns of each synthesized sample; performance of each product in the reaction and statistical analysis of the data.

\section{Author Contributions}

The manuscript was written through contributions of all authors. All authors have given approval to the final version of the manuscript.

\section{Funding Sources}

This study was funded by the Vicerrectoría de Investigación y Extensión (VIE) at Universidad Industrial de Santander (UIS). I.D.M.V. is grateful for the funding provided by Minciencias for his $\mathrm{PhD}$ studies. J.T.G.S. thanks project 1102-721-50962: "Desarrollo de alternativas catalíticas para la reducción y valorización de emisiones de gases de efecto invernadero típicas de pozos y refinerías petroleras por combustión catalitica de VOCs y transformación de $\mathrm{CO}_{2}$ y $\mathrm{CH}_{4}$ en gas de síntesis" for funding. V.G.B.M. thanks the Agencia Nacional de Hidrocarburos (ANH) and Minciencias for project 1102-847-69842: "Desarrollo de una estrategia catalítica para un proceso de in-situ upgrading acoplado con procesos de combustión in-situ para optimizar la producción y mejorar la calidad de crudos pesados y extra-pesados colombianos por reacciones de transferencia de hidrógeno".

\section{Acknowledgment}

Authors thank the kind help from Laboratorio de Microscopía-UIS under the direction of Prof. C.A Rios for SEM imaging.

\section{References}

(1) Margeta, K.; Farkaš, A. Introductory Chapter: Zeolites - From Discovery to New Applications on the Global Market. Zeolites - New Challenges 2020, 1-10. https://doi.org/10.5772/intechopen.92907. 
(2) Abdelrahman, O. A.; Vinter, K. P.; Ren, L.; Xu, D.; Gorte, R. J.; Tsapatsis, M.; Dauenhauer, P. J. Simple Quantification of Zeolite Acid Site Density by Reactive Gas Chromatography. Catal. Sci. Technol. 2017, 7 (17), 3831-3841. https://doi.org/10.1039/C7CY01068K.

(3) Xu, R.; Pang, W.; Yu, J.; Huo, Q.; Chen, J. Chemistry of Zeolites and Related Porous Materials: Synthesis and Structure; 2010. https://doi.org/10.1002/9780470822371.

(4) Šolcová, O.; Matějová, L.; Topka, P.; Musilová, Z.; Schneider, P. Comparison of Textural Information from Argon(87 K) and Nitrogen(77 K) Physisorption. J Porous Mater 2011, 18 (5), 557565. https://doi.org/10.1007/s10934-010-9409-x.

(5) Niu, G.; Huang, Y.; Chen, X.; He, J.; Liu, Y.; $\mathrm{He}$, A. Thermal and Hydrothermal Stability of Siliceous Y Zeolite and Its Application to HighTemperature Catalytic Combustion. Applied Catalysis B: Environmental 1999, 21 (1), 63-70. https://doi.org/10.1016/S0926-3373(99)00009-0.

(6) Cundy, C. S.; Cox, P. A. The Hydrothermal Synthesis of Zeolites: Precursors, Intermediates and Reaction Mechanism. Microporous and Mesoporous Materials $\quad \mathbf{2 0 0 5}, \quad 82 \quad$ (1-2), 1-78. https://doi.org/10.1016/j.micromeso.2005.02.016.

(7) Cundy, C. S.; Cox, P. A. The Hydrothermal Synthesis of Zeolites: History and Development from the Earliest Days to the Present Time. Chem. Rev. 2003, $103 \quad$ (3), 663-702. https://doi.org/10.1021/cr020060i.

(8) Bacakova, L.; Vandrovcova, M.; Kopova, I.; Jirka, I. Applications of Zeolites in Biotechnology and Medicine - a Review. Biomater. Sci. 2018, 6 (5), 974-989. https://doi.org/10.1039/C8BM00028J.

(9) Kornas, A.; Olszówka, J. E.; Urbanova, M.; Mlekodaj, K.; Brabec, L.; Rathousky, J.; Dedecek, J.; Pashkova, V. Milling Activation for the Solvent-Free Synthesis of the Zeolite Mordenite. Eur. J. Inorg. Chem. 2020, 2020 (29), 2791-2797. https://doi.org/10.1002/ejic.202000320.

(10) Wu, Q.; Wang, X.; Qi, G.; Guo, Q.; Pan, S.; Meng, X.; Xu, J.; Deng, F.; Fan, F.; Feng, Z.; Li, C.; Maurer, S.; Müller, U.; Xiao, F. S. Sustainable Synthesis of Zeolites without Addition of Both Organotemplates and Solvents. Journal of the American Chemical Society 2014, 136 (10), 40194025. https://doi.org/10.1021/ja500098j.
(11) Oleksiak, M. D.; Rimer, J. D. Synthesis of Zeolites in the Absence of Organic StructureDirecting Agents: Factors Governing Crystal Selection and Polymorphism. Reviews in Chemical Engineering 2014, 30 (1), 1-49. https://doi.org/10.1515/revce-2013-0020.

(12) Zeolites and Catalysis: Synthesis, Reactions and Applications, 1st ed.; Čejka, J., Corma, A., Zones, S., $\quad$ Eds.; Wiley, 2010. https://doi.org/10.1002/9783527630295.

(13) Structure Commission of the International Zeolite Association. Framework Type MFI. 2017.

(14) Wu, Q.; Meng, X.; Gao, X.; Xiao, F. S. Solvent-Free Synthesis of Zeolites: Mechanism and Utility. Accounts of Chemical Research 2018, 51 (6), 1396-1403.

https://doi.org/10.1021/acs.accounts.8b00057.

(15) Wang, Y.; Duan, H.; Tan, Z.; Meng, X.; Xiao, F. S. Illuminating Solvent-Free Synthesis of Zeolites. Dalton Transactions 2020, 49 (21), 69396944. https://doi.org/10.1039/d0dt00142b.

(16) Ren, L.; Wu, Q.; Yang, C.; Zhu, L.; Li, C.; Zhang, P.; Zhang, H.; Meng, X.; Xiao, F. S. SolventFree Synthesis of Zeolites from Solid Raw Materials. Journal of the American Chemical Society 2012, 134 (37), 15173-15176. https://doi.org/10.1021/ja3044954.

(17) Nada, M. H.; Larsen, S. C.; Gillan, E. G. Solvent-Free Synthesis of Crystalline ZSM-5 Zeolite: Investigation of Mechanochemical Pre-Reaction Impact on Growth of Thermally Stable Zeolite Structures. Solid State Sciences 2019, 94 (May), 1522.

https://doi.org/10.1016/j.solidstatesciences.2019.05. 009 .

(18) Nada, M. H.; Gillan, E. G.; Larsen, S. C. Mechanochemical Reaction Pathways in SolventFree Synthesis of ZSM-5. Microporous and Mesoporous Materials 2019, 276 (July 2018), 23-28. https://doi.org/10.1016/j.micromeso.2018.09.009.

(19) Nada, M. H.; Larsen, S. C.; Gillan, E. G. Mechanochemically-Assisted Solvent-Free and Template-Free Synthesis of Zeolites ZSM-5 and Mordenite. Nanoscale Advances 2019, 1 (10), 39183928. https://doi.org/10.1039/c9na00399a.

(20) Chen, S.; Guan, D.; Zhang, Y.; Wang, Z.; Jiang, N. Composition and Kinetic Study on Template- and Solvent-Free Synthesis of ZSM-5 
Using Leached Illite Clay. Microporous and Mesoporous Materials 2019, 285, 170-177. https://doi.org/10.1016/j.micromeso.2019.05.009.

(21) Zhu, L.; Zhang, J.; Wang, L.; Wu, Q.; Bian, C.; Pan, S.; Meng, X.; Xiao, F.-S. Solvent-Free Synthesis of Titanosilicate Zeolites. J. Mater. Chem. A 2015, 3 (27), 14093-14095. https://doi.org/10.1039/C5TA02680F.

(22) Pashkova, V.; Mlekodaj, K.; Klein, P.; Brabec, L.; Zouzelka, R.; Rathousky, J.; Tokarova, V.; Dedecek, J. Mechanochemical Pretreatment for Efficient Solvent-Free Synthesis of SSZ-13 Zeolite. Chem. Eur. J. 2019, 25 (52), 12068-12073. https://doi.org/10.1002/chem.201902107.

(23) Yucun Cui; Zheng Yan; Mengli Li; Jie Zhu; Longfeng Zhu; Hong Yao; Xuebo Cao. Solvent-Free Synthesis of All Silica Beta Zeolite in the Presence of Tetraethylammonium Bromide. Crystals 2018, 8 (2), 73. https://doi.org/10.3390/cryst8020073.

(24) Ji, Y.; Wang, Y.; Xie, B.; Xiao, F. S. Zeolite Seeds: Third Type of Structure Directing Agents in the Synthesis of Zeolites. Comments on Inorganic Chemistry 2016, $36 \quad$ (1), 1-16. https://doi.org/10.1080/02603594.2015.1031375.

(25) Petkowicz, D. I.; Canal, S.; Finger, P. H.; Mignoni, M. L.; dos Santos, J. H. Z. Synthesis of Hybrid Zeolites Using a Solvent-Free Method in the Presence of Different Organosilanes. Microporous and Mesoporous Materials 2017, 241, 98-106. https://doi.org/10.1016/j.micromeso.2016.11.030.

(26) Gao, W.; Amoo, C. C.; Zhang, G.; Javed, M.; Mazonde, B.; Lu, C.; Yang, R.; Xing, C.; Tsubaki, N. Insight into Solvent-Free Synthesis of MOR Zeolite and Its Laboratory Scale Production. Microporous and Mesoporous Materials 2019, 280, 187-194. https://doi.org/10.1016/j.micromeso.2019.01.041.

(27) Majano, G.; Borchardt, L.; Mitchell, S.; Valtchev, V.; Pérez-Ramírez, J. Rediscovering Zeolite Mechanochemistry-A Pathway beyond Current Synthesis and Modification Boundaries. Microporous and Mesoporous Materials 2014, 194, 106-114.

https://doi.org/10.1016/j.micromeso.2014.04.006.

(28) Meng, X.; Xiao, F.-S. Green Routes for Synthesis of Zeolites. Chem. Rev. 2014, 114 (2), 1521-1543. https://doi.org/10.1021/cr4001513.

(29) Iyoki, K.; Itabashi, K.; Okubo, T. Progress in Seed-Assisted Synthesis of Zeolites without Using
Organic Structure-Directing Agents. Microporous and Mesoporous Materials 2014, 189, 22-30. https://doi.org/10.1016/j.micromeso.2013.08.008.

(30) Wu, Q.; Liu, X.; Zhu, L.; Ding, L.; Gao, P.; Wang, X.; Pan, S.; Bian, C.; Meng, X.; Xu, J.; Deng, F.; Maurer, S.; Müller, U.; Xiao, F.-S. Solvent-Free Synthesis of Zeolites from Anhydrous Starting Raw Solids. J. Am. Chem. Soc. 2015, 137 (3), 1052-1055. https://doi.org/10.1021/ja5124013.

(31) Wu, J.; Hamada, M. Experiments: Planning, Analysis, and Optimization, Second.; Wiley, 2009.

(32) Ji, Y.; Yang, H.; Yan, W. Strategies to Enhance the Catalytic Performance of ZSM-5 Zeolite in Hydrocarbon Cracking: A Review. Catalysts 2017, 7 (12), 367. https://doi.org/10.3390/catal7120367.

(33) Sumitani, K.; Namatame, A. Xylene Isomerization: K. Sumitani; A. Namatame Teijin Petrochemical Industries Ltd. Jpn Kokai Tokkyo Koho 86,238,344, Oct. 23,1986; Appl. Apr. 15,1985. Zeolites $\quad \mathbf{1 9 8 8}, \quad 8 \quad$ (4), 341. https://doi.org/10.1016/S0144-2449(88)80145-3.

(34) Chen, L.; Xue, T.; Wu, H.; Wu, P. Hierarchical ZSM-5 Nanocrystal Aggregates: SeedInduced Green Synthesis and Its Application in Alkylation of Phenol with Tert -Butanol. RSC Adv. 2018, $8 \quad$ (5), $2751-2758$. https://doi.org/10.1039/C7RA12811H.

(35) Krishnan, V.; Ojha, K.; Pradhan, N. C. Alkylation of Phenol with Tertiary Butyl Alcohol over Zeolites. Org. Process Res. Dev. 2002, 6 (2), 132-137. https://doi.org/10.1021/op010077n.

(36) Liang, T.; Chen, J.; Qin, Z.; Li, J.; Wang, P.; Wang, S.; Wang, G.; Dong, M.; Fan, W.; Wang, J. Conversion of Methanol to Olefins over H-ZSM-5 Zeolite: Reaction Pathway Is Related to the Framework Aluminum Siting. ACS Catal. 2016, 6 (11), 7311-7325. https://doi.org/10.1021/acscatal.6b01771.

(37) Nagose, N. R.; Dukhande, V. Alkylation of Phenol with Tert-Butyl Alcohol Using (1-(4Sulfonic Acid) Butyl Triethylammonium p-Toulene Sulfonic Acid [SBTEA][PTSA]. IJARSE 2017, 6, 8.

(38) Sakthivel, A.; Dapurkar, S. E.; Gupta, N. M.; Kulshreshtha, S. K.; Selvam, P. The Influence of Aluminium Sources on the Acidic Behaviour as Well as on the Catalytic Activity of Mesoporous HAlMCM-41 Molecular Sieves. Microporous and Mesoporous Materials 2003, 65 (2-3), 177-187. 
https://doi.org/10.1016/j.micromeso.2003.08.004.

(39) Dumitriu, E.; Meloni, D.; Monaci, R.; Solinas, V. Liquid-Phase Alkylation of Phenol with t-Butanol over Various Catalysts Derived from MWW-Type Precursors. Comptes Rendus Chimie 2005, 8 (3-4), 441-456. https://doi.org/10.1016/j.crci.2004.10.007.

(40) Jiang, T.; Lu, L.; Le, S.; Ma, Y.; Dai, L.; Zhao, H.; Zhao, Q. Improvement of the Catalytic Activity of MCM-48 Synthesized from Metakaolinite in the Alkylation of Phenol with Tert-Butyl Alcohol. Applied Clay Science 2015, 109-110, 1-7. https://doi.org/10.1016/j.clay.2015.03.005.

(41) Adam, F.; Hello, K. M.; Ali, T. H. Solvent Free Liquid-Phase Alkylation of Phenol over Solid Sulfanilic Acid Catalyst. Applied Catalysis A: General 2011, 399 (1-2), 42-49. https://doi.org/10.1016/j.apcata.2011.03.039.

(42) Condon, J. B. Surface Area and Porosity: Determinations by Physisorption Measurement, Classical Theories and Quantum Theory, Second Edition.; Condon, J. B., Ed.; Elsevier, 2020.

(43) Cychosz, K. A.; Thommes, M. Progress in the Physisorption Characterization of Nanoporous Gas Storage Materials. Engineering 2018, 4 (4), 559566. https://doi.org/10.1016/j.eng.2018.06.001.

(44) Viswanadham, N.; Kumar, M. Effect of Dealumination Severity on the Pore Size Distribution of Mordenite. Microporous and Mesoporous Materials 2006, 92 (1-3), 31-37. https://doi.org/10.1016/j.micromeso.2005.07.049.

(45) Kokotailo, G.; Lawton, S.; Olson, D.; Meier, W. Structure of Synthetic Zeolite ZSM- 5. Nature 1978, 272, 437-438.

(46) Shen, H.-Y.; Judeh, Z. M. A.; Ching, C. B.; Xia, Q.-H. Comparative Studies on Alkylation of Phenol with Tert-Butyl Alcohol in the Presence of Liquid or Solid Acid Catalysts in Ionic Liquids. Journal of Molecular Catalysis A: Chemical 2004, $212 \quad$ (1-2), 301-308. https://doi.org/10.1016/j.molcata.2003.11.007.

(47) Ren, N.; Bronić, J.; Jelić, T. A.; Palčić, A.; Subotić, B. Seed-Induced, Structure Directing AgentFree Crystallization of Sub-Micrometer Zeolite ZSM-5: A Population Balance Analysis. Crystal Growth \& Design 2012, 12 (4), 1736-1745. https://doi.org/10.1021/cg200981d.

(48) Kosanović, C.; Bronić, J.; Subotić, B.; Smit,
I.; Stubičar, M.; Tonejc, A.; Yamamoto, T. Mechanochemistry of Zeolites: Part 1. Amorphization of Zeolites A and X and Synthetic Mordenite by Ball Milling. Zeolites 1993, 13 (4), 261-268. 2449(93)90004-M.

(49) Kosanović, C.; Čižmek, A.; Subotić, B.; Šmit, I.; Stubičar, M.; Tonejc, A. Mechanochemistry of Zeolites: Part 3. Amorphization of Zeolite ZSM-5 by Ball Milling. Zeolites 1995, 15 (1), 51-57. https://doi.org/10.1016/0144-2449(94)00018-N.

(50) Baxter, E. F.; Bennett, T. D.; Cairns, A. B.; Brownbill, N. J.; Goodwin, A. L.; Keen, D. A.; Chater, P. A.; Blanc, F.; Cheetham, A. K. A Comparison of the Amorphization of Zeolitic Imidazolate Frameworks (ZIFs) and Aluminosilicate Zeolites by Ball-Milling. Dalton Trans. 2016, 45 (10), $4258-4268$. https://doi.org/10.1039/C5DT03477A.

(51) Buzimov, A. Y.; Kulkov, S. N.; Eckl, W.; Pappert, S.; Gömze, L. A.; Kurovics, E.; Kocserha, I.; Géber, R. Effect of Mechanical Treatment on Properties of Zeolites with Chabazite Structure. $J$. Phys.: Conf. Ser. 2017, 790, 012004. https://doi.org/10.1088/1742-6596/790/1/012004.

(52) Kim, S. D.; Noh, S. H.; Seong, K. H.; Kim, W. J. Compositional and Kinetic Study on the Rapid Crystallization of ZSM-5 in the Absence of Organic Template under Stirring. Microporous and Mesoporous Materials 2004, 72 (1-3), 185-192. https://doi.org/10.1016/j.micromeso.2004.04.024.

(53) Maldonado, M.; Oleksiak, M. D.; Chinta, S.; Rimer, J. D. Controlling Crystal Polymorphism in Organic-Free Synthesis of Na-Zeolites. Journal of the American Chemical Society 2013, 135 (7), 26412652. https://doi.org/10.1021/ja3105939.

(54) Davis, M. E. Zeolites from a Materials Chemistry Perspective. Chemistry of Materials 2014, 26 (1), 239-245. https://doi.org/10.1021/cm401914u.

(55) Iyoki, K.; Itabashi, K.; Okubo, T. Progress in Seed-Assisted Synthesis of Zeolites without Using Organic Structure-Directing Agents. Microporous and Mesoporous Materials 2014, 189, 22-30. https://doi.org/10.1016/j.micromeso.2013.08.008.

(56) Jansen, J. C.; van der Gaag, F. J.; van Bekkum, H. Identification of ZSM-Type and Other 5Ring Containing Zeolites by i.r. Spectroscopy. Zeolites 1984, 4 (4), 369-372. 
https://doi.org/10.1016/0144-2449(84)90013-7.

(57) Shukla, D. B.; Pandya, V. P. Estimation of Crystalline Phase in ZSM-5 Zeolites by Infrared Spectroscopy. Journal of Chemical Technology \& Biotechnology 1989, 44 (2), 147-154. https://doi.org/10.1002/jctb.280440206.

(58) Das, G.; Kakati, N.; Lee, S. H.; Karak, N.; Yoon, Y. S. Water Soluble Sodium Sulfate Nanorods as a Versatile Template for the Designing of Copper Sulfide Nanotubes. j. nanosci. nanotech. 2014, 14 (6),

4455-4461.

https://doi.org/10.1166/jnn.2014.8282.

(59) Bharmoria, P.; Gehlot, P. S.; Gupta, H.; Kumar, A. Temperature-Dependent Solubility Transition of $\mathrm{Na}_{2} \mathrm{SO}_{4}$ in Water and the Effect of $\mathrm{NaCl}$ Therein: Solution Structures and Salt Water Dynamics. J. Phys. Chem. B 2014, 118 (44), 12734 12742. https://doi.org/10.1021/jp507949h.

(60) Okorafor, O. Solubility and Density Isotherms for the Sodium Sulfate-Water-Methanol System. Journal of Chemical \& Engineering Data 1999, 44, 488-490. https://doi.org/10.1021/je980243v.

(61) Alipour, S. M.; Halladj, R.; Askari, S. Effects of the Different Synthetic Parameters on the Crystallinity and Crystal Size of Nanosized ZSM-5 Zeolite. Reviews in Chemical Engineering 2014, 30 (3). https://doi.org/10.1515/revce-2014-0008.

(62) Montgomery, D. C. Design and Analysis of Experiments, 5th ed.; John Wiley: New York, 2001.

(63) Loftus, G. R. On Interpretation of Interactions. Memory \& Cognition 1978, 6 (3), 312319. https://doi.org/10.3758/BF03197461.

(64) Wagenmakers, E.-J.; Krypotos, A.-M.; Criss, A. H.; Iverson, G. On the Interpretation of Removable Interactions: A Survey of the Field 33 Years after Loftus. Mem Cogn 2012, 40 (2), 145-160. https://doi.org/10.3758/s13421-011-0158-0.

(65) Kho, H. X.; Bae, S.; Bae, S.; Kim, B.-W.; Kim, J. S. Planetary Ball Mill Process in Aspect of Milling Energy. j. Korean Powder Metall. Inst. 2014, $21 \quad$ (2), 155-164. https://doi.org/10.4150/KPMI.2014.21.2.155.

(66) Do, J.-L.; Friščić, T. Chemistry 2.0: Developing a New, Solvent-Free System of Chemical Synthesis Based on Mechanochemistry. Synlett 2017, 28 (16), 2066-2092. https://doi.org/10.1055/s-00361590854 .
(67) Zhang, J.; Lu, X.; Wang, Z. Control of Crystallization Rate and Morphology of Zeolite Silicalite-1 in Solvent-Free Synthesis. Microporous and Mesoporous Materials 2019, 283, 14-24. https://doi.org/10.1016/j.micromeso.2019.03.044.

(68) Van Tendeloo, L.; Gobechiya, E.; Breynaert, E.; Martens, J. A.; Kirschhock, C. E. A. Alkaline Cations Directing the Transformation of FAU Zeolites into Five Different Framework Types. Chem. Commun. 2013, 49 (100), 11737. https://doi.org/10.1039/c3cc47292b.

(69) Sano, T.; Itakura, M.; Sadakane, M. High Potential of Interzeolite Conversion Method for Zeolite Synthesis. J. Jpn. Petrol. Inst. 2013, 56 (4), 183-197. https://doi.org/10.1627/jpi.56.183.

(70) Nedyalkova, R.; Montreuil, C.; Lambert, C.; Olsson, L. Interzeolite Conversion of FAU Type Zeolite into CHA and Its Application in NH3-SCR. Top Catal 2013, 56 (9-10), 550-557. https://doi.org/10.1007/s11244-013-0015-4.

(71) Tang, L.; Haw, K.-G.; Zhang, Y.; Fang, Q.; Qiu, S.; Valtchev, V. Fast and Efficient Synthesis of SSZ-13 by Interzeolite Conversion of Zeolite Beta and Zeolite L. Microporous and Mesoporous Materials 2019, 280, 306-314. https://doi.org/10.1016/j.micromeso.2019.02.021.

(72) Goel, S.; Zones, S. I.; Iglesia, E. Synthesis of Zeolites via Interzeolite Transformations without Organic Structure-Directing Agents. Chem. Mater. 2015, 27 (6), 2056-2066. https://doi.org/10.1021/cm504510f.

(73) Thommes, M.; Kaneko, K.; Neimark, A. V.; Olivier, J. P.; Rodriguez-Reinoso, F.; Rouquerol, J.; Sing, K. S. W. Physisorption of Gases, with Special Reference to the Evaluation of Surface Area and Pore Size Distribution (IUPAC Technical Report). Pure and Applied Chemistry 2015, 87 (9-10), 1051-1069. https://doi.org/10.1515/pac-2014-1117.

(74) Adamson, A.; Gast, A. Physical Chemistry of Surfaces, 6th ed.; 1997.

(75) Donohue, M. D.; Aranovich, G. L. Classification of Gibbs Adsorption Isotherms. Advances in Colloid and Interface Science 1998, 7677, 137-152. https://doi.org/10.1016/S00018686(98)00044-X.

(76) Müller, U.; Unger, K. K. Sorption Studies on Large ZSM-5 Crystals: The Influence of Aluminium Content, The Type of Exchangeable Cations and the 
Temperature on Nitrogen Hysteresis Effects. In Studies in Surface Science and Catalysis; Elsevier, 1988; Vol. 39, pp 101-108. https://doi.org/10.1016/S0167-2991(09)60734-5.

(77) Emeis, C. A. Determination of Integrated Molar Extinction Coefficients for Infrared Absorption Bands of Pyridine Adsorbed on Solid Acid Catalysts. Journal of Catalysis. 1993, pp 347354. https://doi.org/10.1006/jcat.1993.1145.

(78) Woolery, G. L.; Kuehl, G. H. On the Nature of Framework Brønsted and Lewis Acid Sites in ZSM-5. Zeolites 1997, 19 (4), 288-296. https://doi.org/10.1016/S0144-2449(97)00086-9.

(79) van Santen, R. A. Theory of Brønsted Acidity in Zeolites. Studies in Surface Science and $\begin{array}{llll}\text { Catalysis 1994, } 85 & \text { (C), 273-294. }\end{array}$ https://doi.org/10.1016/S0167-2991(08)60771-5.

(80) Li, G.; Pidko, E. A. The Nature and Catalytic Function of Cation Sites in Zeolites: A Computational Perspective. ChemCatChem 2019, 11 (1), 134-156. https://doi.org/10.1002/cctc.201801493.

(81) Ravi, M.; Sushkevich, V. L.; van Bokhoven, J. A. Towards a Better Understanding of Lewis Acidic Aluminium in Zeolites. Nat. Mater. 2020, 19 (10), 1047-1056. https://doi.org/10.1038/s41563020-0751-3.

(82) Dumitriu, E.; Hulea, V. Effects of Channel Structures and Acid Properties of Large-Pore Zeolites in the Liquid-Phase Tert-Butylation of Phenol. Journal of Catalysis 2003, 218 (2), 249-257. https://doi.org/10.1016/S0021-9517(03)00159-3.

(83) Jansang, B.; Nanok, T.; Limtrakul, J. Structure and Reaction Mechanism of Alkylation of Phenol with Methanol over H-FAU Zeolite: An ONIOM Study. J. Phys. Chem. C 2008, 112 (2), 540547. https://doi.org/10.1021/jp077246b.

(84) Xu, L.; Wu, S.; Guan, J.; Wang, H.; Ma, Y.; Song, K.; Xu, H.; Xing, H.; Xu, C.; Wang, Z.; Kan, Q. Synthesis, Characterization of Hierarchical ZSM5 Zeolite Catalyst and Its Catalytic Performance for Phenol Tert-Butylation Reaction. Catalysis Communications 2008, 9 (6), 1272-1276. https://doi.org/10.1016/j.catcom.2007.11.018.

(85) Nie, X.; Janik, M. J.; Guo, X.; Liu, X.; Song, C. Reaction Mechanism of Tert-Butylation of Phenol with Tert-Butyl Alcohol over H- $\beta$ Zeolite: An ONIOM Study. Catalysis Today 2011, 165 (1), 120-
128. https://doi.org/10.1016/j.cattod.2010.11.070.

(86) Zhao, Z.; Shi, H.; Wan, C.; Hu, M. Y.; Liu, Y.; Mei, D.; Camaioni, D. M.; Hu, J. Z.; Lercher, J. A. Mechanism of Phenol Alkylation in Zeolite $\mathrm{H}$ BEA Using In Situ Solid-State NMR Spectroscopy. J. Am. Chem. Soc. 2017, 139 (27), 9178-9185. https://doi.org/10.1021/jacs.7b02153.

(87) Gackowski, M.; Datka, J. Acid Properties of Hierarchical Zeolites Y. Molecules 2020, 25 (5), 1044. https://doi.org/10.3390/molecules25051044.

(88) Wang, C.; Zhang, L.; Huang, X.; Zhu, Y.; Li, G. (Kevin); Gu, Q.; Chen, J.; Ma, L.; Li, X.; He, Q.; Xu, J.; Sun, Q.; Song, C.; Peng, M.; Sun, J.; Ma, D. Maximizing Sinusoidal Channels of HZSM-5 for High Shape-Selectivity to p-Xylene. Nat Commun 2019, 10 (1), 4348. https://doi.org/10.1038/s41467019-12285-4.

(89) Khalil, I.; Thomas, K.; Jabraoui, H.; Bazin, P.; Maugé, F. Selective Elimination of Phenol from Hydrocarbons by Zeolites and Silica-Based Adsorbents-Impact of the Textural and Acidic Properties. Journal of Hazardous Materials 2020, 384 , 121397. https://doi.org/10.1016/j.jhazmat.2019.121397.

(90) Khalil, I.; Jabraoui, H.; Maurin, G.; Lebègue, S.; Badawi, M.; Thomas, K.; Maugé, F. Selective Capture of Phenol from Biofuel Using Protonated Faujasite Zeolites with Different Si/Al Ratios. $J$. Phys. Chem. C 2018, 122 (46), 26419-26429. https://doi.org/10.1021/acs.jpcc.8b07875.

(91) Vjunov, A.; Fulton, J. L.; Huthwelker, T.; Pin, S.; Mei, D.; Schenter, G. K.; Govind, N.; Camaioni, D. M.; Hu, J. Z.; Lercher, J. A. Quantitatively Probing the Al Distribution in Zeolites. J. Am. Chem. Soc. 2014, 136 (23), 82968306. https://doi.org/10.1021/ja501361v. 